\title{
Finite element modelling for the assessment of tunnel-induced damage to a masonry building
}

May 15, 2017

\author{
W. N. Yiu, H. J. Burd and C. M. Martin \\ Department of Engineering Science, University of Oxford, Parks Road, Oxford, OX1 3PJ \\ W. N. Yiu, email: wing.yiu@eng.ox.ac.uk \\ H. J. Burd, email: harvey.burd@eng.ox.ac.uk \\ C. M. Martin, email: chris.martin@eng.ox.ac.uk
}

\begin{abstract}
The likely severity and extent of cracking damage in existing masonry buildings caused by shallow tunnelling in urban areas is typically assessed in practice using a phased sequence of calculations of increasing complexity. If initial assessments (e.g. with the building modelled as an elastic beam) suggest that damage could be significant, or for high heritage-value buildings, it may be appropriate to conduct more detailed assessments using 3D numerical analysis. The current paper demonstrates the application of 3D finite element modelling in this context. Models are developed to quantify the effect of shallow tunnelling on an example masonry building founded on strip footings, considering both single and twin tunnel scenarios in a typical London soil profile. The analyses use appropriate constitutive models for the soil and the masonry, and allow for the possibility of slippage and gapping at the soil-foundation interface. The results presented here focus on the interaction between the soil and the building (via its foundations) and on the influence of explicitly modelled window and door openings. It is shown that useful damage predictions can be obtained from 3D analysis of a single facade and foundation, without needing to model a complete building. The study also highlights some of the limitations of current elastic beam assessment methods.
\end{abstract}

\section{Introduction}

The construction of shallow tunnels (e.g. for a new underground transportation system) inevitably generates local ground deformations. In an urban environment, these deformations may, in turn, cause damage 
to any nearby buildings on the ground surface. Damage may be particularly significant for load-bearing masonry structures, which typically behave in a brittle manner, and even minor damage is undesirable in high heritage-value buildings. During the planning of new urban tunnelling projects, detailed calculation procedures are therefore required to identify buildings at risk and to make reliable assessments of the likely extent of any tunnel-induced structural damage.

Current methods for assessing masonry buildings at risk of tunnel-induced settlement damage are typically based on a phased sequence of calculations of increasing detail and sophistication (e.g. Mair et al., 1996; Harris \& Franzius, 2005; Burland et al., 2012). Assessments are initially conducted using a relatively simple analytical approach in which the building is modelled as an elastic beam that deforms according to the greenfield tunnel-induced ground movements that are estimated to occur at foundation level (Burland \& Wroth, 1974; Boscardin \& Cording, 1989). This procedure is referred to in the current paper as the 'elastic beam assessment' (EBA) method. In this procedure, the severity of the damage is assumed to be correlated with the maximum tensile strain developed in the building, as determined from the model. If this approach (which is generally assumed to be conservative (e.g. Mair et al., 1996)) indicates a risk of significant damage, then further, more refined, calculations may be conducted to obtain more detailed damage assessments.

Numerical modelling, e.g. using finite element analysis, provides a means of conducting refined assessments in cases where the application of the EBA method (including extensions to account for the stiffness of the building, e.g. Potts \& Addenbrooke (1997)) is inconclusive. However, although there are examples in the literature comparing finite element modelling results with field data for buildings that have been affected by tunnelling (e.g. Amorosi et al., 2014; Fargnoli et al., 2015; Bilotta et al., 2017), there are no obvious signs that this type of computational modelling is being routinely undertaken in civil engineering practice for project-based assessment purposes. It is presumed that the various practical difficulties that need to be addressed, notably uncertainties as to how the soil and building material models should be specified and calibrated, combined with an apparent cautious conservatism among practitioners and clients, limit the application and development of finite element-based procedures for tunnel-induced damage assessments. The current paper demonstrates the use of 3D finite element analysis in this context. The emphasis is on the development of computational methods that avoid undue complexity, while providing results that are useful for practical assessment purposes, with suggested methods for data processing. The current work demonstrates that the benefits of relatively detailed 3D finite element analysis can be exploited with an acceptable computational cost.

The paper is structured around the performance of an example masonry building that is intended to 
be representative of low-rise masonry buildings on shallow foundations in Central London. The main focus of the paper is a modelling approach termed ' $3 \mathrm{D}$ isolated facade' analysis in which the building facades are assumed to act as independent structural elements. Models employing this approach have the merit that they are simpler to develop, and faster to compute, than more detailed approaches in which the whole building is represented (here termed '3D complete building' analysis). Moreover, the isolated facade modelling approach can readily be incorporated within the current phased assessment process as an intermediate step between the EBA method (which is also based on the isolated facade assumption) and more detailed numerical models.

The paper has four main purposes. Firstly, it provides a demonstration of the types of modelling procedures that are feasible with current computing hardware and commercial finite element software. Secondly, the modelling results are used to elucidate the various mechanisms that are active in this particular tunnel-soil-building interaction scenario. Thirdly, the paper explores the extent to which isolated facade models (with and without openings) provide an acceptable expedient for practical damage assessment purposes. Fourthly, the numerical results provide a basis for understanding the nature and impact of some of the simplifications and assumptions inherent in the EBA method, at least for the particular tunnelling scenarios investigated here.

\section{Specification of example problem}

The building and tunnel arrangements considered in the study are shown in Fig. 1. The dimensions of the building and the layout of the openings in the front and rear facades are based on previous work (Burd et al., 2000; Wisser et al., 2005; Pickhaver et al., 2010). Two building sizes are investigated: a two-storey variant $(H=8 \mathrm{~m})$ and a three-storey variant $(H=12 \mathrm{~m})$; the two-storey variant is depicted in Fig 1. For comparison purposes, a small number of analyses have been conducted (referred to below as 'plain facade') in which the openings are absent. An appropriate representation of the foundation, including the soil-foundation interaction, is important when modelling tunnel-soil-building interaction problems of this type (Yiu et al., 2017). The foundation in the current example is a strip footing of width $1 \mathrm{~m}$, thickness $0.5 \mathrm{~m}$ and embedded depth $1 \mathrm{~m}$. These dimensions are based on the foundations for the low-rise residential masonry building described in Withers (2001).

The assumed soil conditions (Fig. 1(d)) are representative of those in central London, where typically a layer of Terrace Gravel overlies the London Clay. It is noted that layers of alluvium and made ground usually exist above the Terrace Gravel. These superficial soils have been omitted from the current model 
for simplicity. Moreover, major masonry buildings in London often have one or more basements and are typically founded either on the Terrace Gravel or, for deep basements, on the London Clay (e.g. Harris, 2001; Viggiani \& Standing, 2001). In the current model, no attempt is made to represent a basement. To enable the footings to bear directly on the Terrace Gravel, the gravel is assumed to extend upwards to the ground surface. As a consequence, the thickness of the gravel layer in the model is rather larger than is typically encountered in London. The Terrace Gravel is assumed to be dry, with the water table at the base of the layer. The London Clay is assumed to behave in an undrained manner; this is considered to be an appropriate representation of the soil behaviour during, and immediately after, the tunnelling process, but is clearly not adequate for modelling long-term effects.

Analyses have been conducted for horizontal single and twin tunnels installed beneath the building at eccentricities $e$ in the range $0 \leqslant e \leqslant 30 \mathrm{~m}$, see Figs 1(d) and (e). In all cases (except the skew tunnel example introduced at the end of the paper) the tunnels are orthogonal to the front and rear facades of the building. Tunnel construction is modelled as a single process (i.e. construction of the entire length of tunnel within the finite element model is simulated in a single analysis stage). Although this procedure does not allow transient effects due to incremental tunnel construction to be computed, it provides an efficient means of establishing the deformations induced in the building after the tunnel heading has passed. The tunnel diameter $(11 \mathrm{~m})$ and depth $(23 \mathrm{~m})$ are intended to be representative of typical Crossrail platform tunnels (Crossrail, accessed January 31, 2017; NCE, 2009). A tunnel volume loss of 1.5\% is assumed, corresponding to the 'moderately conservative' volume loss adopted for concourse and platform tunnels in the Crossrail project (Dulake, 2011).

Two different modelling approaches are adopted:

- 3D isolated facade analysis, in which a single facade (the front or rear facade, together with its strip footing) is modelled in isolation. Although certain 3D effects (e.g. due to return walls and foundations) are excluded, these analyses have the merit that parametric studies can be conducted relatively quickly. The isolated facade approach could therefore be an attractive option for practical assessment purposes. Although the facade is modelled as a planar structure, 3D modelling is required to capture the interaction between the foundation and the ground.

- 3D complete building analysis, in which all facades, internal and end walls are included in the model, though the floors and roof are excluded on the basis that they are unlikely to contribute significantly to the stiffness of the building or to require detailed consideration in the damage assessment process. This approach provides an enhanced level of detail, but at the expense of 
additional geometrical complexity and longer computation time. Comparisons between the results of the 3D complete building analyses and the corresponding 3D isolated facade analyses provide a means of assessing the accuracy and usefulness of the isolated facade modelling approach.

In both approaches, lintels are included above all of the window and door openings in the facades to avoid tensile failure in the masonry due to local sagging effects.

\section{Finite element modelling procedures}

The numerical calculations were performed using the finite element program Abaqus v2016 (Dassault Systèmes Simulia Corp., Providence, RI, USA). Advanced constitutive models (involving the implementation of bespoke code and requiring detailed calibration) were employed for the Terrace Gravel and London Clay. For practical assessment purposes, it may be feasible to employ simpler constitutive models and accept the likely lower fidelity of the modelling, although this is not pursued in the current paper.

\subsection{Meshes}

Finite element meshes consisting of the building, the foundations and the soil (incorporating either single or twin tunnels) were generated using Abaqus CAE. Following Wongsaroj et al. (2007), the depth from the ground surface to the base of each mesh is $50 \mathrm{~m}$. Typical meshes for the 3D isolated facade analyses and the 3D complete building analyses are shown in Figs 2 and 3 respectively. For the 3D isolated facade meshes in Fig. 2, symmetry about the mid-plane of the facade is exploited. For the 3D complete building mesh in Fig. 3 (noting that in the current study the analyses are limited to $e=0$ ), symmetry about the vertical plane passing through the tunnel centre is exploited. In both sets of meshes, the degrees of freedom on the base boundary are fixed in all directions and all vertical boundaries have roller supports.

Six-noded shell elements (Abaqus element type STRI65) with five Gauss points through the thickness are used to model the facade, walls and lintels. The foundation and the soil are modelled by 10-noded tetrahedral elements (Abaqus element type C3D10). The building is linked to the foundations using the Abaqus keyword *EMBEDDED ELEMENT. Data on the numbers of elements employed in the meshes are given in Table 1. 


\subsection{Constitutive models}

\subsubsection{Terrace gravel}

The extended Mohr-Coulomb (EMC) model of Doherty \& Muir Wood (2013) is used to represent the Terrace Gravel. This model was originally developed to model shallow foundations; it is therefore regarded as being suitable for the present work. The model has been implemented as an Abaqus userdefined material model (UMAT), using an explicit stress integration scheme with adaptive sub-stepping and error control as detailed in Sloan et al. (2001), as part of the current study.

The EMC model employs a hardening form of the Mohr-Coulomb yield surface; hardening is linked to plastic deviatoric strain and mobilised friction angle. Within the yield surface, the soil behaves elastically; elastic behaviour is defined by the small-strain shear modulus, $G_{0}$, and Poisson's ratio, $v$. The plastic and hardening behaviours are specified by a peak friction angle, $\phi_{p}$, constant volume friction angle, $\phi_{c v}$, attraction, $a$, and hardening parameter, $\beta$. The flow rule is based on a variant of the original Cam Clay plastic potential. The model provides representations of the degradation in stiffness as the soil is sheared towards failure, and also the behaviour on unloading (initial unloading is represented in the model as an elastic process). Unloading is an important feature of the current analysis, since redistribution of vertical load on the strip footing occurs as a consequence of tunnel construction. This redistribution requires that the bearing pressures beneath some parts of the footing will reduce, while the pressures below other parts will increase.

Calibration of the model was conducted by fitting it (in an approximate sense) to the nonlinear elastic Mohr-Coulomb model previously employed by Jurečič et al. (2013) (Tables 4 and 5 of Jurečič et al. (2013)) to represent the Terrace Gravel. The calibrated parameters for the EMC model are listed in Table 2. The values of $G_{0}, v$ and $\phi_{p}$ are taken directly from Jurečič et al. (2013), and critical state shearing is assumed at failure so that $\phi_{c v}=\phi_{p}$ (refer to Doherty \& Muir Wood (2013) for background on this assumption). Following Doherty \& Muir Wood (2013), a small value of attraction $(a=4 \mathrm{kPa})$ is adopted. The hardening parameter $\beta$ is determined by finding an approximate fit to the small-strain stiffness data plotted in Jurečič et al. (2013). The resulting variation of tangent shear modulus with deviatoric strain from the EMC model is plotted in Fig. 4. The dependence of soil stiffness on stress level is implemented in an approximate way by specifying a variation of shear modulus with depth that is based on the geostatic mean effective stress (i.e. in which the building is absent) subject to a minimum of $G_{0}=2000 \mathrm{kPa}$. A dry unit weight of $19.5 \mathrm{kN} / \mathrm{m}^{3}$ and a lateral earth pressure coefficient of $K_{0}=0.425$ (Withers et al., 2001) are adopted in the model. As suggested by Doherty \& Muir Wood (2013), the 
initial yield surface is specified by applying a factor of 1.06 to the initial mobilised friction angle.

\subsubsection{London Clay}

The multiple yield surface kinematic hardening model of Houlsby (1999) is used to represent the undrained behaviour of the London Clay. This model has been employed in previous related research (e.g. Burd et al., 2000) and has been implemented in a UMAT as described in Dong et al. (2016).

On the basis of data in Fig. 5.6(b) of Withers et al. (2001), the undrained shear strength $s_{u}$ (units of $\mathrm{kPa}$ ) is assumed to vary with depth below the clay surface $z_{c}$ (in units of metres) as:

$$
s_{u}=100+8 z_{c}
$$

The small-strain shear modulus is assumed to be $G_{0}=500 s_{u}$, again based on data in Withers et al. (2001). The bulk modulus is taken as $K=50 G_{0}$, which corresponds to an undrained Poisson's ratio of 0.49 . The bulk unit weight of the clay is assumed to be $20 \mathrm{kN} / \mathrm{m}^{3}$, and the initial geostatic stress state is established with $K_{0}=1$.

For consistency with previous work (e.g. Burd et al., 2000), a total of nine inner yield surfaces are used, with a fixed outer von Mises yield surface. The non-dimensional constitutive parameters controlling the inner yield surfaces are the same as those adopted in Burd et al. (2000), giving the normalised evolution of tangent shear modulus with shear strain shown in Fig. 5.

\subsubsection{Masonry and lintels}

A key aspect to consider in the choice of constitutive model for the masonry building is the loss of strength and stiffness that occurs when tensile cracking develops. However, since the focus of the current work is the development of relatively straightforward computational procedures for practical risk assessment purposes, detailed considerations such as the analysis of likely geometric cracking patterns are unnecessary. Moreover, a homogenised approach is preferred rather than attempting to model the details of individual masonry blocks and mortar joints. It is noted that in any practical assessment exercise, the constitutive properties of the masonry will typically be uncertain; anything more than a relatively simple modelling approach is therefore unlikely to be justified.

The masonry in this study was represented using the 'concrete damaged plasticity' model available as a built-in model in Abaqus. This model is based on the formulation in Lee \& Fenves (1998) and has been used previously by Furtmuller \& Adam (2011) for the analysis of masonry buildings. The model is 
designed particularly to represent cyclic degradation (via the use of a damage parameter). In the current analyses, however, the model parameters are set so that the material remains undamaged. Prior to failure, the masonry is elastic, with Young's modulus $E_{m}=3 \mathrm{GPa}$ and Poisson's ratio $v_{m}=0.2$ (Giardina et al., 2013). When loaded in uniaxial tension, the material is linear elastic until a fracture stress, $f_{t}=50 \mathrm{kPa}$, is reached. This value of $f_{t}$ is comparable to data employed in previous studies; e.g. Furtmuller \& Adam (2011) and Giardina et al. (2013) both adopt $100 \mathrm{kPa}$ as the tensile strength of masonry. The value of 50 $\mathrm{kPa}$ employed in the current work is intended to provide a realistic lower bound on strength.

Masonry would be expected to exhibit a softening response after the onset of cracking. From a numerical perspective, however, a softening post-cracking response is undesirable because of pathological mesh-dependent behaviour and the likelihood of numerical difficulties. Accordingly, the post-failure gradient of the uniaxial tensile stress-strain response in the current model is specified to be a small positive value, $f E_{m}$ with $f=0.01$.

The unit weight of the masonry is assumed to be $19 \mathrm{kN} / \mathrm{m}^{3}$ (Giardina et al., 2013). To ensure that the overall loading on the foundation is representative of a real building, allowance is made (by using an artificially increased unit weight for the masonry) for the weight of the roof, floors, windows, internal plaster and internal fixtures and fittings. In the current analysis, following Losacco et al. (2014), the unit weight of the masonry is set to $23.75 \mathrm{kN} / \mathrm{m}^{3}$, i.e. an uplift of $25 \%$ on the actual unit weight. For convenience, the unit weight of the lintels is set to the same value. The lintels are assumed to be made from concrete; they are modelled as linearly elastic with a Young's modulus of 9 GPa and a Poisson's ratio of 0.2 .

\subsubsection{Foundation and foundation-soil interface}

The footing is assumed to be constructed from masonry, and is represented by the same constitutive model that is employed for the building. For convenience in the calculation of the geostatic stresses, the unit weight of the footing is set equal to that of the surrounding soil. It is noted that strip footings of low-rise masonry buildings might alternatively be constructed from concrete (e.g. the Moodkee Street buildings in Withers (2001)) which would presumably result in a stiffer building response. The assumption of masonry footings is thought to provide a conservative approach for damage prediction.

The possibility of sliding or gapping at the soil-foundation interface, as observed in some recent centrifuge model tests reported by Farrell et al. (2014), is accommodated in the analyses by specifying a frictional contact interaction with zero tensile strength. A friction coefficient of $\mu=0.3$, selected to be approximately intermediate between smooth and fully rough, is employed. 


\subsection{Tunnel modelling procedure}

When finite element analysis is used to determine the greenfield ground settlements caused by tunnelling, the computed settlement trough is typically rather wider than that obtained using conventional empirical approaches based on Gaussian settlement curves (e.g. New \& O’Reilly, 1991). It is widely recognised (e.g. Addenbrooke et al., 1997; Jurečič et al., 2013) that the computation of realistic greenfield settlement curves requires constitutive models (such as those employed in the current work) that can model the nonlinear small-strain stiffness of the soil. Moreover, the modelling of ground loss by imposing prescribed displacements at the tunnel perimeter has been found to be a useful way of achieving plausible computed surface deformations. In the current work, the prescribed-displacement ground loss approach used by Amorosi et al. (2014) is adopted. The displacements prescribed at the tunnel perimeter consist of radial shrinkage combined with a rigid vertical movement, such that the invert of the tunnel remains at its initial position. This procedure introduces a fictitious vertical force on the tunnel boundary; it cannot therefore be used reliably to compute soil deformations local to the tunnel. It is considered, however, that this procedure is acceptable for a study focused on the effect of ground movements on buildings with shallow foundations, on the basis that this interaction occurs some distance from the tunnel perimeter. Provided reasonable greenfield settlement profiles are obtained, the actual conditions in the neighbourhood of the tunnel are regarded as being of secondary importance for the building-focused analyses undertaken here.

Some of the calculations presented in this paper are concerned with the analysis of twin tunnels. Construction of these tunnels is modelled as a simultaneous event. It is acknowledged that, in practice, twin tunnels are likely to be constructed sequentially, such that the soil movements induced by the second tunnel may be influenced by the presence of the first tunnel (Addenbrooke \& Potts, 2001). Tunnel-tunnel interactions of this sort are not considered in the current study.

\subsection{Calculation sequence}

Initially, the shell elements modelling the building are deactivated, although the continuum elements representing the foundation are active. Geostatic stresses are then initialised throughout the soil and the footing, using the unit weight and $K_{0}$ values specified above. $K_{0}$ for the footing is set equal to that of the surrounding soil. Next, the building is introduced; the stiffness of the building is first added to the model, then its self-weight is applied incrementally. Tunnel construction is then simulated; the boundary of the tunnel is fixed and the internal soil elements are removed, then the displacements required to model the ground loss are imposed on the tunnel perimeter. All calculation steps are conducted using the automatic incrementation procedures provided in Abaqus. 


\section{Results processing}

When applying the EBA method, damage categories are commonly assumed to correlate with the magnitude of the maximum tensile strain estimated to occur in the building (e.g. Burland, 2001; Mair et al., 1996). Consistent with this approach, a strain-based damage correlation is employed in the present work, though certain issues require careful consideration as described below.

Firstly, the construction of the building in the finite element analysis induces initial strains in the facades, walls and foundations. In the current study, these initial strains are typically of the order of 10 $\mu \varepsilon$ (microstrain), rising to about $100 \mu \varepsilon$ around the openings. Since the building construction process adopted in the model is highly simplified, the computed initial strains do not provide a precise representation of the strains actually developed in a real building after construction. Moreover, additional post-construction building strains are likely to occur as a consequence of further differential settlements and seasonal effects. It is impractical to include these pre-existing strains directly within a tunnel-soilbuilding model and so, consistent with the EBA approach, assessments of tunnel-induced damage are based on the additional tensile strains developed in the building facades due to tunnel construction. Since a nonlinear constitutive model is employed for the masonry, the strains induced in the building during the simulated construction process will have some influence on the subsequent behaviour, but this influence is not considered in the processes described in the current paper. A convenient approach for computing the additional tunnel-induced strains is to attach a layer of 'ghost' membrane elements - with very small stiffness - to the surfaces of the building facades and walls immediately prior to simulating the tunnel construction process. The computed strains within the ghost elements then provide a direct indication of the tunnel-induced strains. It is noted that for the 3D complete building analyses, the facades and walls may experience some out-of-plane bending. The ghost elements are specified to deform with the central plane of the shell elements (Abaqus keyword *TIE, NO THICKNESS). Any strain gradients in the shell elements caused by out-of-plane bending are therefore excluded from the subsequent data processing.

Secondly, when openings for windows and doors exist in the building facades, the computed strains are affected by stress singularities that occur at any internal corners (e.g. Hills \& Dini, 2011). In practical terms, this means that the maximum value of the computed tensile strain is liable to increase without limit as the mesh is refined around the corners of the openings. Any damage correlation based on the maximum value of the computed tensile strains, $\varepsilon^{t}$, may therefore suffer from undesirable mesh-dependent effects. In the current work, this difficulty is addressed via a 'characteristic strain' approach. In this procedure, 
the severity of the tensile strains induced in the facade is quantified in terms of a characteristic value of the tensile strain that is not exceeded in an area $\eta A_{\text {facade }}$, where $A_{\text {facade }}$ is the total area of facade being assessed and $\eta$ is a characteristic proportion. Here the characteristic proportion is arbitrarily chosen to be $\eta=0.99$, and the corresponding characteristic tensile strain is denoted $\varepsilon_{99}^{t}$. A further consideration is that it may not always be appropriate to categorise the damage using a single (characteristic) strain value. A single metric, for example, does not indicate whether the damage is localised or more widely distributed. An alternative method, in which the damage is characterised in terms of the proportion of the facade area experiencing a particular category of damage, is also employed in the analysis of the results.

In the results presented below, strain and displacement data relate to the net values induced by the tunnelling process, and tensile strains are positive.

\section{Results}

\subsection{Run times}

Typical run times (employing one core (Abaqus parameter cpus =1) of Xeon Processor E5-2640 v3) were of the order of 1.5 hours for the isolated facade analyses and 2.5 hours for the complete building analyses.

\subsection{Greenfield profiles}

Greenfield settlement profiles, computed at the level of the base of the foundation in the absence of a building, are plotted in Figs 6(a) and (b), together with Gaussian curves fitted to the computed profiles (employing superposition for the twin tunnels). The trough width parameter for the Gaussian curves is $K=0.57$; this may be compared with empirical data (e.g. O'Reilly \& New, 1982) suggesting that $K$ varies from 0.2 for granular materials to 0.7 for soft silty clay.

Although a ground loss of $1.5 \%$ was prescribed at the tunnel perimeter, the actual volume of the settlement trough at foundation level was found to be equivalent to a volume loss of $1.65 \%$ for the single tunnel and $1.64 \%$ for each of the twin tunnels. An investigation of the mismatch between the volume losses at the tunnel and at the surface indicated that, although dilational volumetric strains occur in the gravel in peripheral regions, these are more than offset by compressive volumetric strains in the gravel directly above the tunnel. A discussion of the compressive-dilational behaviour that occurs around tunnels in drained soil is given in Marshall et al. (2012). 


\subsection{D isolated facade analyses}

The results of a parametric study for the 3D isolated facade (Fig. 2) are presented below. The facade meshes incorporate the geometric arrangement of openings shown in Fig. 1(b), though for comparison purposes some calculations (termed 'plain facade') have been conducted in which openings and lintels are absent. The results presented below all relate to the standard case where the facade has openings, except when it is explicitly stated that the results relate to a plain facade.

\subsubsection{Zero tunnel eccentricity}

The computed settlement profiles at the base of the footing for single and twin tunnels with $e=0$ are plotted in Fig. 7. These data indicate the expected behaviour that (i) the facades do not conform to the greenfield displacements, and (ii) the $H=12 \mathrm{~m}$ facade responds in a stiffer way than the $H=8 \mathrm{~m}$ facade. Also plotted in Fig. 7 are the computed settlements for the plain facades. As expected, the plain facades behave in a stiffer manner compared with the facades with openings. Fig. 7(c) shows that a gap opens up between the foundation and the underlying soil at the centre of the plain facade with $H=12 \mathrm{~m}$, for the single tunnel case. This type of gapping behaviour has also been observed in centrifuge model tests (Farrell et al., 2014).

The computed horizontal displacements and horizontal strains at the base of the footing, and in the soil adjacent to the base of the footing, are shown in Fig. 8. For both the single tunnel (Fig. 8(a)) and twin tunnel (Fig. 8(b)) cases, the horizontal displacements of the footing are substantially lower in magnitude than (and typically in the opposite direction to) those occurring in the adjacent soil; significant sliding clearly occurs at the soil-footing interface.

The horizontal strains developed in the footing and in the adjacent soil are shown in Figs 8(c) and (d). The strains induced in the footing are substantially lower in magnitude than those in the soil; they are also substantially less than the computed greenfield horizontal strains (Figs 6(c) and (d)). This is a significant result and is consistent with a range of previous field monitoring data from London (e.g. Burland et al., 2004; Dimmock \& Mair, 2008) in which the observed horizontal strains at foundation level in masonry buildings affected by tunnel-induced settlements are relatively small, compared with the estimated greenfield horizontal strains. Moreover, the nature of the soil-foundation interaction observed in the finite element results is at odds with the procedure typically employed in the EBA method (Boscardin \& Cording, 1989) in which the greenfield horizontal strains estimated to occur in the soil are combined additively with the strains developed in the building by structural (bending and shear) action.

The computed normal and shear tractions developed on the base of the footing are shown in Fig. 9. It 
is clear that inward limiting friction (with $\mu=0.3$ ) is mobilised over most of footing (Figs 9(c) and (d)) except in relatively small zones near the facade midpoint. The construction of the tunnel(s) causes the normal tractions to be redistributed, towards the edges of the facade for the single tunnel case (Fig. 9(a)) and towards the centre of the facade for the twin tunnel case (Fig. 9(b)). Consistent with these redistributed normal tractions, additional settlements develop, which - for both the single and twin tunnel cases - act to reduce the differential settlements induced in the building (Figs 7(a) and (b)). These observations further emphasise the need for a realistic representation of the interaction between the foundation and the ground to achieve reliable estimates of the deformations induced in the building.

The computed tensile strains induced in the facade for single and twin tunnels with $e=0$ are plotted in Fig. 10. Results from the corresponding plain facade analyses are also shown for comparison. The data in Fig. 10(a) (plain facade, single tunnel) indicate a rather complex pattern in which concentrations of strain occur at about $6 \mathrm{~m}$ from the centre of the facade (corresponding roughly to the location of the inflection points, Fig. 7(c)). In Fig. 10(b) (plain facade, twin tunnel) the strain gradients are more uniform, and more obviously consistent with beam action. The strain distributions for the facades with openings (Figs 10(c) and (d)), however, indicate a fundamentally different pattern. Whereas the strains in the plain facade correspond broadly to beam action (although additional local effects are seen in Fig. 10(a)), the facade with openings exhibits a more complex, frame-like action with significant concentrations of strain occurring around the windows. These observations indicate the importance of accounting for openings when determining the distribution and magnitude of the tensile strains developed in a facade. Also shown in Fig. 10 are the $\varepsilon_{99}^{t}$ values for each analysis. In all cases the $\varepsilon_{99}^{t}$ values are larger when openings are incorporated in the facade. This is due to (i) the plain facade being stiffer than the case where openings are present, which reduces the severity of the tunnel-induced settlements, and (ii) the occurrence of strain localisation around the openings.

The tensile strain data for the facade with openings are plotted in Fig. 11 using a stacked bar chart. This form of data presentation (which has previously been employed by Truong-Hong \& Laefer (2013)) provides details of the proportion of the facade area that is affected by different levels of damage, on the basis of the damage categories proposed by Boscardin \& Cording (1989). For the current calculations, around $85 \%$ of each facade area suffers negligible damage (Cat 0 ). A small proportion of the facade, for all of the calculations, is classified as Cat 3 (maximum tensile strain between $1500 \mu \varepsilon$ and $3000 \mu \varepsilon$ ) although, as suggested earlier, the $\varepsilon_{99}^{t}$ values determined from the analysis provide a more realistic metric of the likely level of damage. 


\subsubsection{Effect of tunnel eccentricity}

Fig. 12 shows the computed characteristic tensile strain $\varepsilon_{99}^{t}$ in the isolated facade for a range of values of tunnel eccentricity. The data show that for both the single and twin tunnel cases, the characteristic strain is at a maximum when $e=0$. Also shown are values of the maximum tensile strain determined using the EBA method (in the form specified by Mair et al. (1996)) in which the facade is partitioned into hogging and sagging parts as appropriate, with $E / G=2.4$ where $E$ and $G$ are assumed values for the Young's modulus and shear modulus, respectively, of the building. The full height of the facade down to foundation level is employed (i.e. $H_{E B A}=9 \mathrm{~m}$ and $13 \mathrm{~m}$ ). Two variants of the method have been adopted. In $\mathrm{EBA}_{A}$ the computed greenfield displacements are applied to the facade, and the computed greenfield horizontal strains are combined with the facade strains, additively, when they are tensile (Boscardin \& Cording, 1989). In $\mathrm{EBA}_{B}$ a modified approach is employed in which the vertical displacements computed at foundation level in the finite element analysis, with the facade present, are applied to the EBA model; no additional horizontal strains from the ground are imposed on the building in this case. The $\mathrm{EBA}_{B}$ approach accounts for the reduced settlements induced in the building as a consequence of its structural action.

It is clear from Fig. 12 that the maximum tensile strains from $\mathrm{EBA}_{A}$ invariably exceed the characteristic strains obtained from the finite element analysis. This is an expected outcome (due to the relatively large greenfield settlements employed in $\mathrm{EBA}_{A}$ ) and is a reassuring confirmation of the conservatism inherent in the EBA method. In contrast, the tensile strains from $\mathrm{EBA}_{B}$ typically fall below the finite element data. The significance of this can be understood in terms of the strain distributions in Figs 10(c) and (d). Although the vertical displacements at foundation level applied to the $\mathrm{EBA}_{B}$ model are identical to those that occur in the finite element model, the presence of the window and door openings (not accounted for in the EBA method) causes strain concentrations to occur at the internal corners.

Although damage assessment of masonry buildings is usually focused on tensile cracking in the facades and walls, loss of serviceability can also occur to windows (e.g. distortion of the frames could lead to cracks developing in the glazing) and to doors (which may become stuck or otherwise inoperable if significant distortions occur). Since the sensitivity of doors and windows to tunnel-induced deformations will depend on the nature of the construction, no attempt is made here to suggest serviceability limits for practical assessment purposes. It is, however, straightforward to quantify the distortions that develop in the openings in the facades in the finite element models. This is achieved by treating each opening as a quadrilateral finite element and evaluating the engineering shear strain, $\gamma$, at the centroid of the opening.

Data on the shear strains developed in each opening of the facade, for $H=8 \mathrm{~m}$, for a single tunnel 
with $e=0$, are shown in Table 3 . The shear strains in several of the openings, particularly the two doors, are significantly larger than those in the adjacent masonry. This is to be expected, because the openings in the facade have zero stiffness assigned to them in the model. The overall shearing distortion of the facade is therefore accommodated, with a low penalty, by distortion of the openings.

\subsection{D complete building analyses}

\subsubsection{Orthogonal tunnel}

Calculations for the complete building (e.g. Fig. 3) have been conducted for building heights of $H=8 \mathrm{~m}$ and $H=12 \mathrm{~m}$, considering both single and twin tunnels orthogonal to the building with $e=0$. The computed maximum principal tensile strains for $H=8 \mathrm{~m}$, single tunnel, are shown in Fig. 13(a), and it is noteworthy that the magnitude and distribution of these strains are very similar to those obtained from the corresponding isolated facade analysis (Fig. 10(c)). The computed vertical and horizontal displacements in the foundation are compared with the corresponding isolated facade data in Figs 13(c) and (d); again, the two sets of data are similar.

Characteristic strains for the four complete building analyses and the corresponding isolated facade analyses are compared in Fig. 14. These data indicate that values of $\varepsilon_{99}^{t}$ computed using the two modelling approaches are comparable; the influence of the return walls and foundations running parallel to the tunnel axis appears to be relatively insignificant in this case. This suggests that, at least for tunnel-building configurations similar to those considered here, isolated facade models are likely to be sufficiently detailed for damage assessment purposes.

\subsubsection{Skew tunnel}

3D complete building finite element analysis allows modelling of a range of geometric tunnel-building configurations. As an example, a skew tunnel analysis has been conducted, with a single tunnel aligned at $45^{\circ}$ to the main building facades with $H=8 \mathrm{~m}$, as shown in Fig. 15(a).

Fig. 15(b) shows the vertical displacement at the footing base for the front facade, compared with the displacements determined from the complete building model, for an orthogonal single tunnel with $e=0$. The differential settlements induced in the skew tunnel case are less than those in the orthogonal tunnel case. Data on computed tensile strains in the front facade are shown in Figs 15(c) and (d). Comparisons with the orthogonal tunnel results in Fig. 13(a) and also in Fig. 15(d) indicate that the front facade experiences less damage when the tunnel is skewed. However, data for the internal and end walls, not presented here, indicate slightly larger tensile strains in the skew tunnel case, although their damage 
categories remains at Cat 0 . On the basis of this comparison, the orthogonal tunnel case appears to provide a more conservative damage estimate. It is noted, however, that transient effects associated with incremental tunnel construction are not included in the current model. Transient effects could be particularly significant for skew configurations in which complex twisting deformation modes may be induced in the building as the tunnel heading passes beneath it (Pickhaver et al., 2010).

\section{Discussion}

(i) Direct numerical analysis of the combined tunnel-soil-building system automatically accounts for the effect of the structural action of the building, as well as the redistribution of bearing pressures on the base of the foundation, in reducing the induced differential settlements. This contrasts with the EBA method, which adopts an uncoupled approach. The current modelling illustrates the conservative nature of the EBA approach.

(ii) Published data from field measurements in London typically indicate that tunnel-induced horizontal strains developed at the base of buildings with shallow foundations are substantially lower in magnitude than those implied by the EBA method. The models described in this paper demonstrate similar behaviour, and indicate that the horizontal coupling between the foundation and the ground, via a sliding mechanism, is relatively weak. In the conventional EBA procedure, tensile strains that are transmitted, additively, from the ground to the building typically have a major impact on the overall damage assessment. The finding that tunnel-induced horizontal strains developed in the soil are not, in fact, transmitted to the building in any meaningful way is significant. This suggests that predictions of the severity of damage are systematically overestimated when the EBA method is employed. A similar conclusion was reached by Burland et al. (2004) on the basis of field data in connection with the Jubilee Line Extension project.

(iii) The finite element results indicate that strain distributions in plain facades are quantitatively and qualitatively different from those that develop in facades with explicitly modelled window and door openings. In particular, strain concentrations that develop around internal corners have a significant influence on the magnitude of the computed strains. The absence of this strain localisation effect in the EBA method reduces the reliability of assessments made using this approach.

(iv) Strain concentrations associated with openings in the facade mean that developing a correlation between the computed strains and the risk of cracking damage is not straightforward. The char- 
acteristic strain approach proposed here is suggested as a practical procedure. The characteristic proportion $\eta=0.99$ employed here has been chosen arbitrarily and it is possible that alternative values of $\eta$ might, in due course, prove to be more appropriate. Moreover, any assessment of the risk of damage could usefully be based on the extent of the damaged area as well as the likely maximum severity. Specific serviceability limits on windows and doors may need to be considered.

(v) For the orthogonal tunnel-building scenarios considered in the paper, the 3D isolated facade analyses and 3D complete building analyses provide similar values of characteristic tensile strain. This suggests that the use of isolated facade models for practical assessments may be acceptable for this particular tunnel-building configuration. Further work is needed, however, to confirm this.

(vi) The 3D complete building analysis with a skew tunnel indicates less damage than the equivalent orthogonal case. However, the performance of the building during the construction of a skew tunnel (which could introduce significant transient effects) has not been considered.

\section{Conclusions}

The paper describes the use of finite element analysis procedures to assess the likely extent of tunnelinduced damage to an existing masonry building. Ground conditions have been selected to be broadly representative of those in Central London. A series of 3D finite element analyses of an example masonry building founded on shallow strip footings is described. The analyses use advanced constitutive models for the soil, a frictional contact model for the soil-foundation interface, and a nonlinear constitutive model for the masonry. Calculations are conducted employing variations of building height, building facade type (with and without openings) and tunnel configuration (single versus twin, various eccentricities, orthogonal versus skew). Tunnel installation is modelled using a relatively simple approach in which the required ground loss is imposed via displacements applied to the tunnel boundary. Two different modelling approaches are explored: 3D isolated facade analysis and 3D complete building analysis. A new procedure is proposed - based on the use of characteristic strains in the masonry - to quantify the severity of the tunnelling-induced damage. Comparisons are provided between the numerical results and the results of equivalent assessments based on the conventional approach of assuming that the building deforms as a flexible elastic beam (referred to in the paper as EBA methods).

The general trends indicated by the finite element analyses are consistent with the expected behaviour: (i) the presence of the building tends to modify the local ground movements, and (ii) reducing the building height or incorporating openings for windows and doors leads to more severe damage. Ad- 
ditionally, the analyses reproduce the commonly observed finding from field measurements that the horizontal strains in the building at foundation level are typically smaller than those in the adjacent ground, and substantially less than would be implied by the commonly used EBA methods. This phenomenon, which is identified as being associated with slippage at the soil-foundation interface, suggests that current assessment methods in which greenfield horizontal strains are imposed directly on a beam model of the building may be unrealistic. Detailed comparisons between the finite element results and EBA methods suggest that in general, the EBA approach is likely to be conservative. However, modifications to the EBA approach in which differential settlements are reduced on account of building stiffness may be unconservative as a result of strain concentrations (not considered in the standard EBA approach) at the corners of any openings that may be present in the facade.

The 3D isolated facade modelling approach is shown to provide a potentially useful tool within the hierarchical phased assessment approach that has evolved to facilitate the assessment of large numbers of buildings that may be affected by urban tunnelling operations. The finite element models are relatively straightforward to set up, and run times on a standard desktop computer are of the order of a few hours. 
Table 1: Types and numbers of elements employed in finite element models

Building meshes

\begin{tabular}{lcccc}
\hline Analysis type & Building height & Part & Element type & Number of elements \\
\hline Isolated facade & $8 \mathrm{~m}$ & facade & STRI65 & 2764 \\
& $12 \mathrm{~m}$ & facade & STRI65 & 4096 \\
& - & footing & C3D10 & 955 \\
Complete building & $8 \mathrm{~m}$ & facade & STRI65 & 4212 \\
(orthogonal) & $12 \mathrm{~m}$ & facade & STRI65 & 6172 \\
& - & footing & C3D10 & 2616 \\
Complete building & $8 \mathrm{~m}$ & facade & STRI65 & 7736 \\
(skew) & - & footing & C3D10 & 5216 \\
\hline
\end{tabular}

Soil meshes

\begin{tabular}{lcccc}
\hline & & & \multicolumn{2}{c}{ Number of elements } \\
\cline { 4 - 5 } Analysis type & Tunnel case & Element type & Gravel & Clay \\
\hline Isolated facade & single & C3D10 & $26465-27902^{*}$ & $17203-19728^{*}$ \\
& twin & C3D10 & $28391-30030^{*}$ & $37802-38837^{*}$ \\
Complete building & single & C3D10 & 31317 & 20410 \\
(orthogonal) & twin & C3D10 & 31317 & 39838 \\
$\begin{array}{l}\text { Complete building } \\
\text { (skew) }\end{array}$ & single & C3D10 & 51095 & 43127 \\
\hline
\end{tabular}

* The range covers models with tunnel eccentricities $0 \leqslant e \leqslant 30 \mathrm{~m}$.

Table 2: Parameters used in extended Mohr-Coulomb model for Terrace Gravel

\begin{tabular}{lcc}
\hline Parameter & & Value \\
\hline Elastic shear modulus & $G_{0}$ & $3 G_{0} / p^{\prime}=2621$ \\
Poisson's ratio & $v$ & 0.2 \\
Peak friction angle & $\phi_{p}$ & $35^{\circ}$ \\
Constant volume friction angle & $\phi_{c v}$ & $35^{\circ}$ \\
Attraction & $a$ & $4 \mathrm{kPa}$ \\
Hardening parameter & $\beta$ & 0.00015 \\
\hline
\end{tabular}

Table 3: Shear strains in window and door openings, facade height $H=8 \mathrm{~m}$, single tunnel with $e=0$. Opening numbers refer to Fig. 1(b)

\begin{tabular}{lcccccccccc}
\hline Opening number & 11 & 12 & 13 & 14 & 15 & 16 & 17 & 18 & 19 & 20 \\
Shear strain: $\mu \varepsilon$ & 422 & 1265 & 2934 & 1998 & 1070 & 1069 & 2001 & 2923 & 1253 & 419 \\
\hline Opening number & 1 & 2 & 3 & 4 & 5 & 6 & 7 & 8 & 9 & 10 \\
Shear strain: $\mu \varepsilon$ & 1173 & 2176 & 3234 & 3026 & 1530 & 1521 & 3026 & 3232 & 2164 & 1173 \\
\hline
\end{tabular}




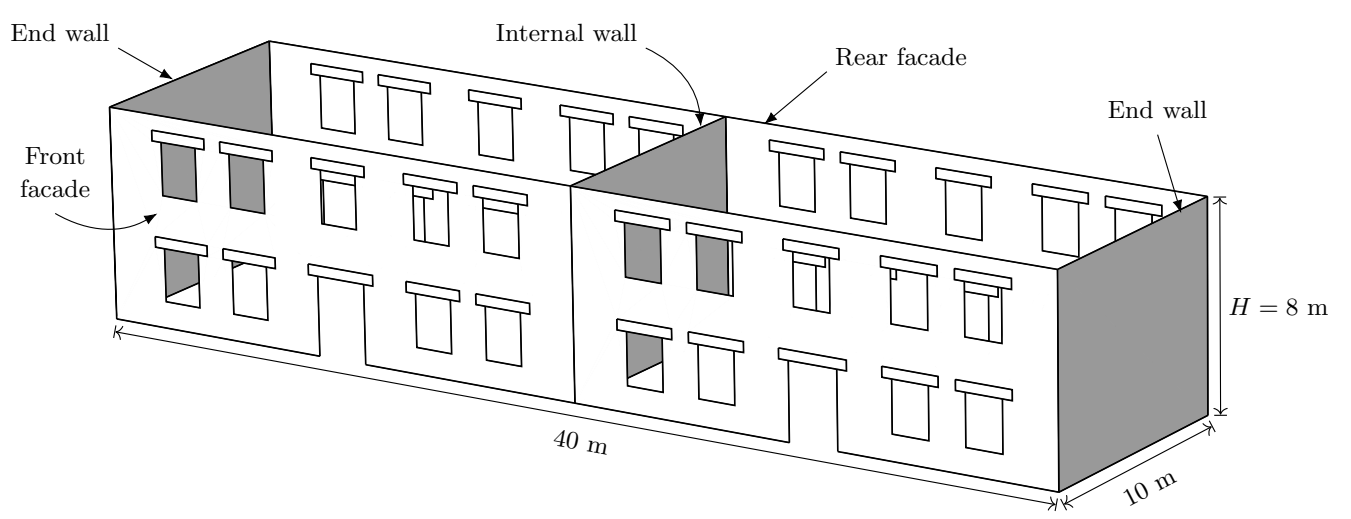

(a)

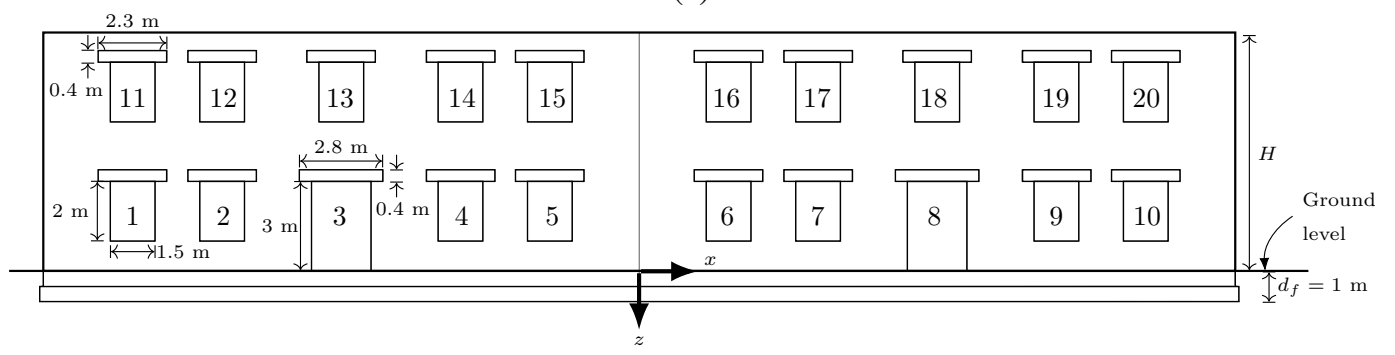

(b)

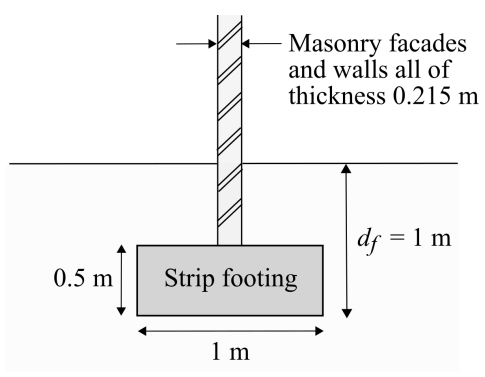

(c)

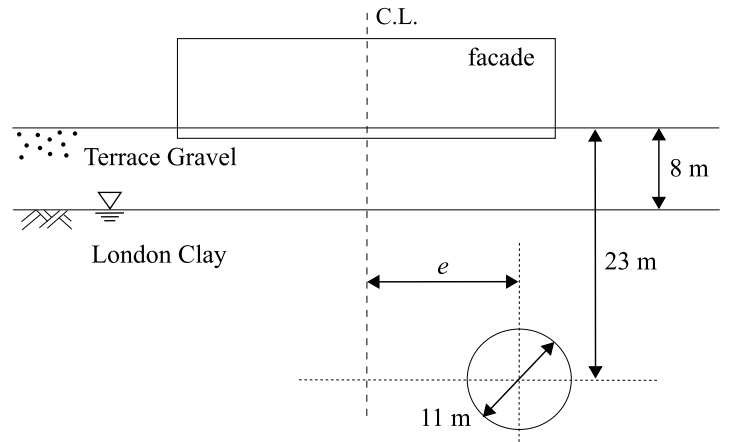

(d)

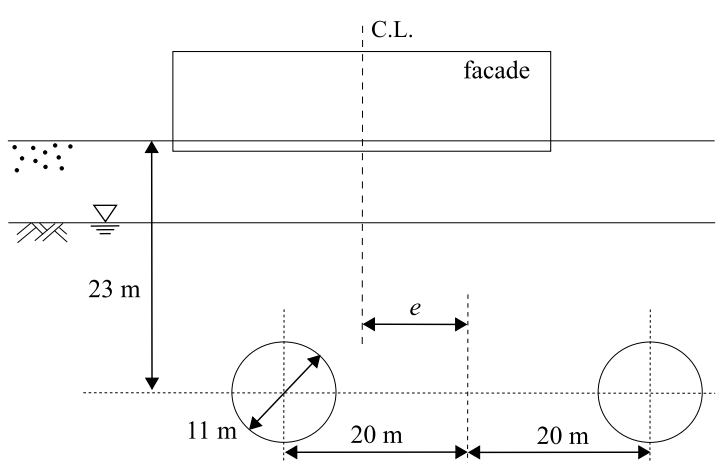

(e)

Figure 1: Building, foundation, soil and tunnel configuration adopted for example analyses: (a) layout and dimensions of building (above-ground height $H=8 \mathrm{~m}$ for two-storey and $12 \mathrm{~m}$ for three-storey); (b) dimensions of facade openings and lintels, also showing coordinate axes; (c) details of masonry and foundation; (d), (e) soil configuration, tunnel dimensions and definition of eccentricity, $e$, for single and twin tunnel analyses respectively 


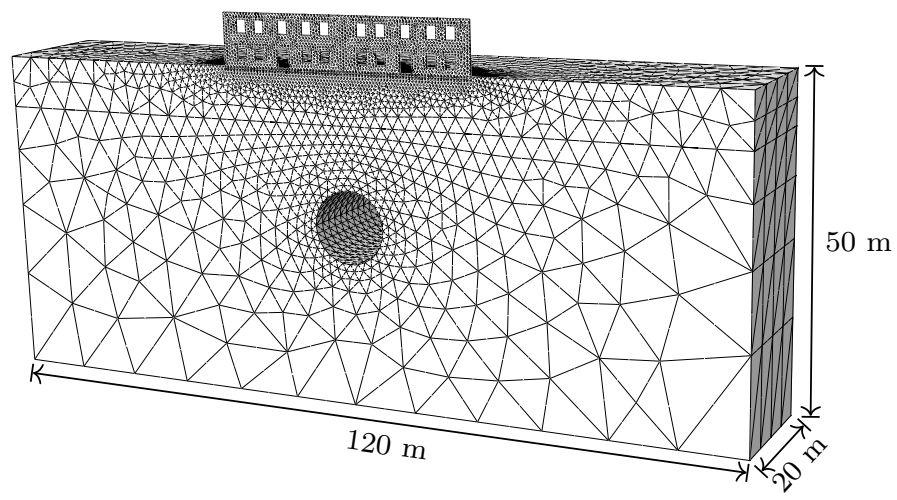

(a)

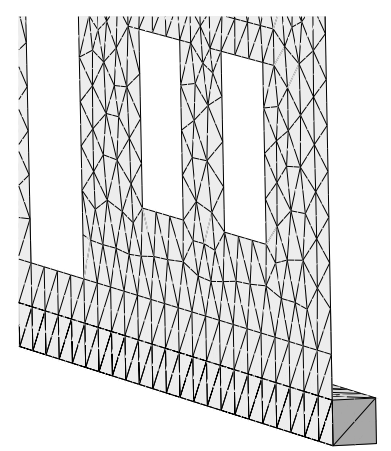

(b)

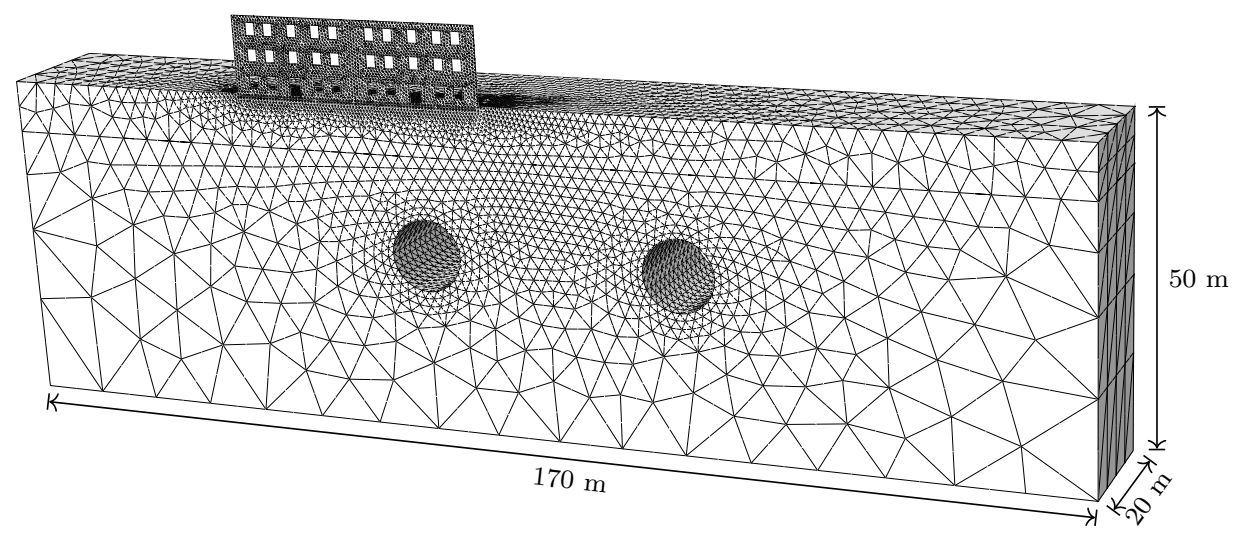

(c)

Figure 2: Typical meshes employed for 3D isolated facade analyses: (a) building height $H=8 \mathrm{~m}$, single tunnel with $e=0$; (b) detail showing facade and foundation; (c) building height $H=12 \mathrm{~m}$, twin tunnels with $e=30 \mathrm{~m}$. Elements internal to the tunnel have been removed for clarity 


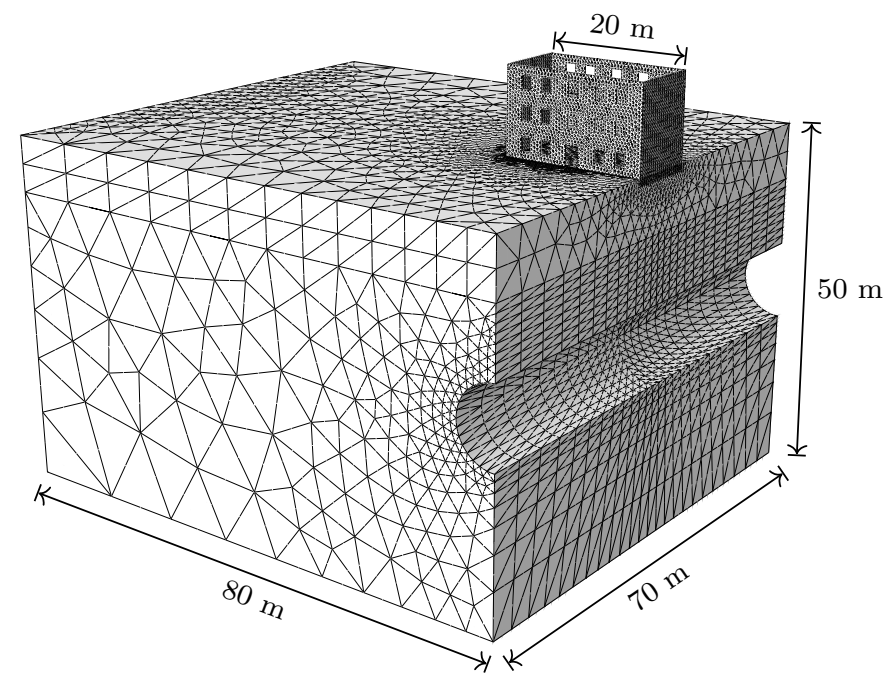

(a)

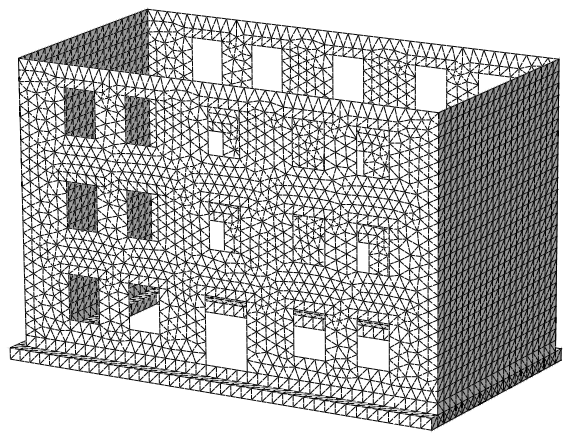

(b)

Figure 3: Typical mesh employed for 3D complete building analyses: (a) building height $H=12 \mathrm{~m}$, single tunnel with $e=0$; (b) detail showing building and foundation 


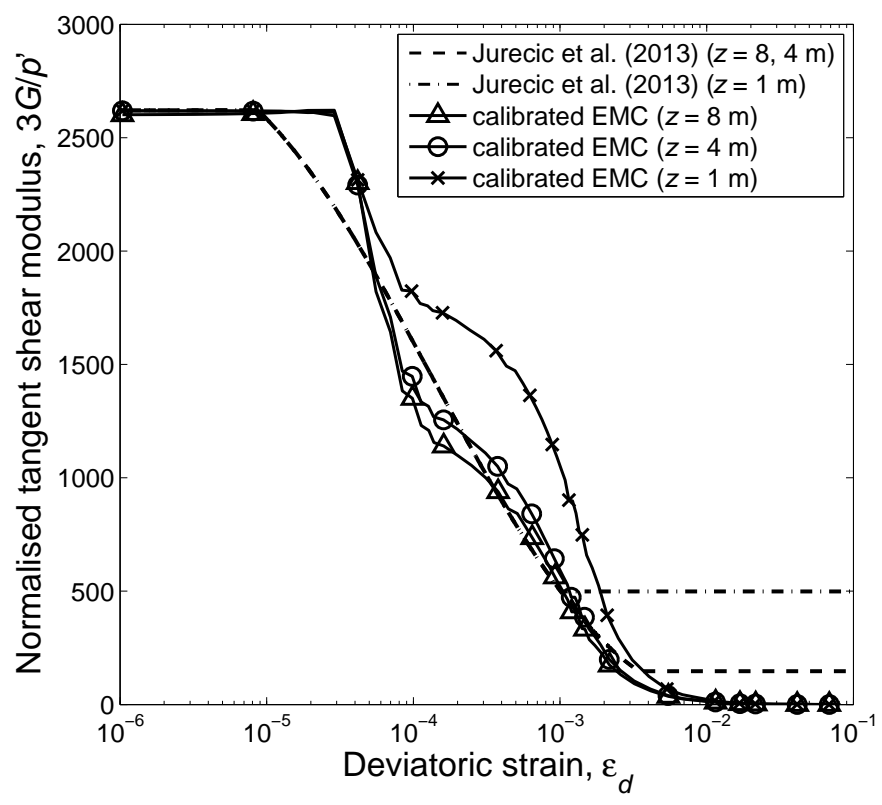

Figure 4: Variation of normalised tangent shear modulus with deviatoric strain at depths $z=8,4$, and $1 \mathrm{~m}$ for the calibrated extended Mohr-Coulomb model. $\varepsilon_{d}$ as defined in Jurečič et al. (2013) 


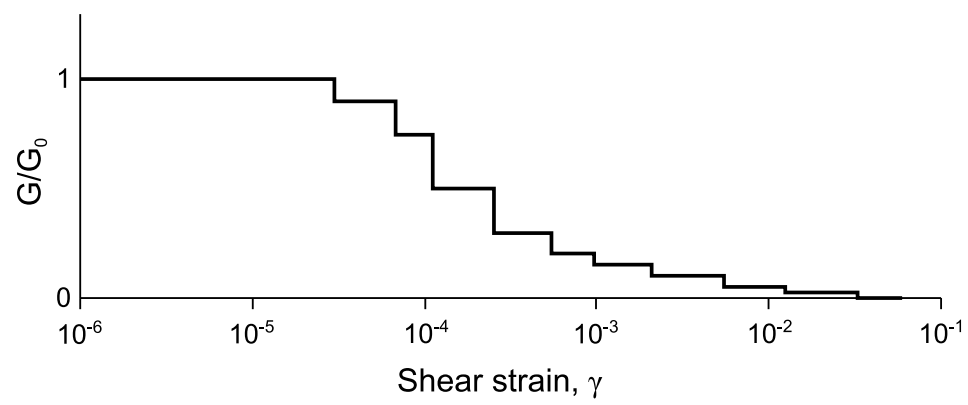

Figure 5: Variation of normalised tangent shear modulus with shear strain for the multiple yield surface model (after Burd et al., 2000) 


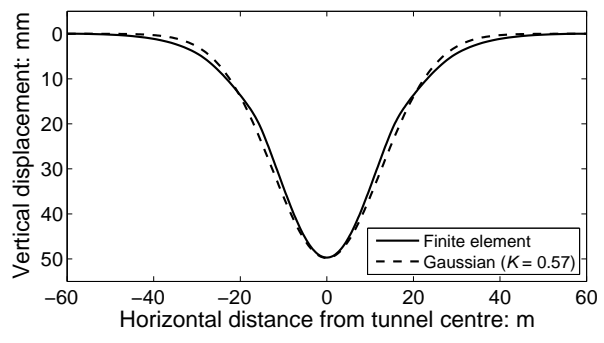

(a)

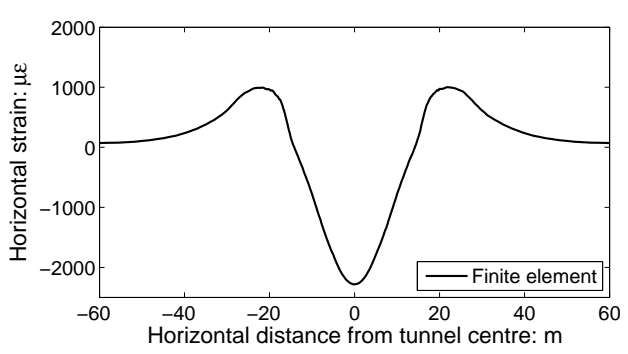

(c)

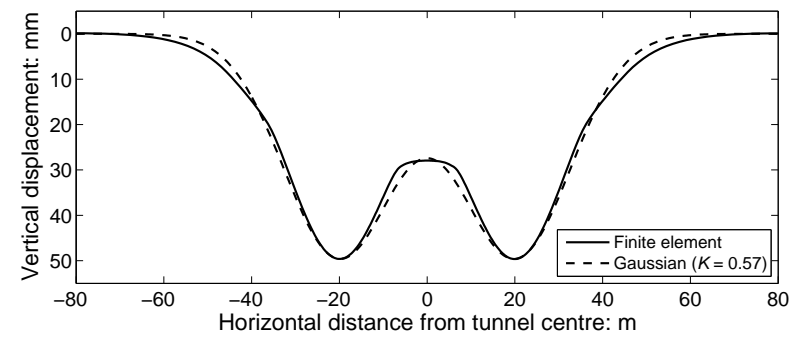

(b)

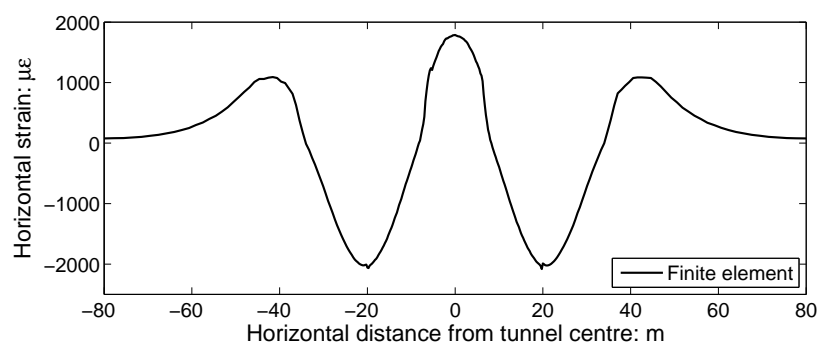

(d)

Figure 6: Greenfield vertical displacements and horizontal strains at foundation base level induced by tunnelling with $e=0$ : (a) vertical displacement, single tunnel; (b) vertical displacement, twin tunnels; (c) horizontal strain, single tunnel; (d) horizontal strain, twin tunnels 


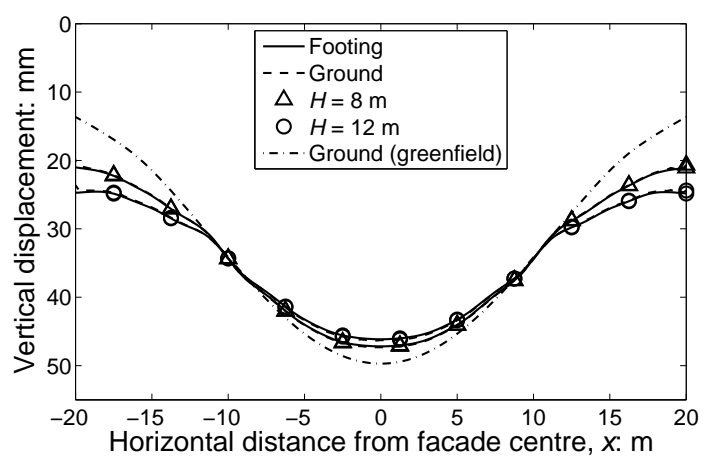

(a)

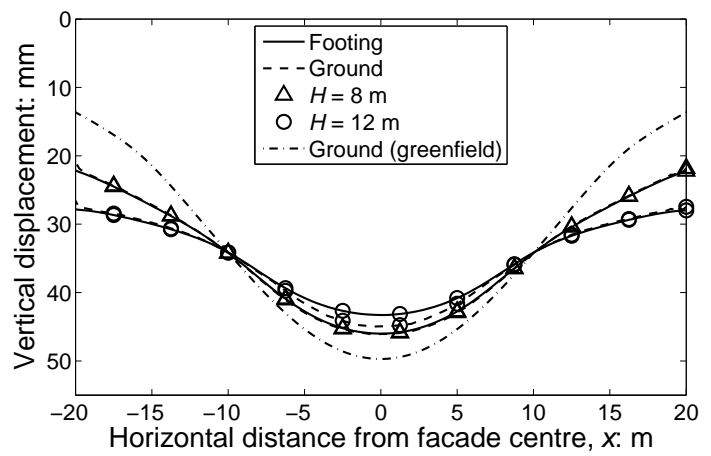

(c)

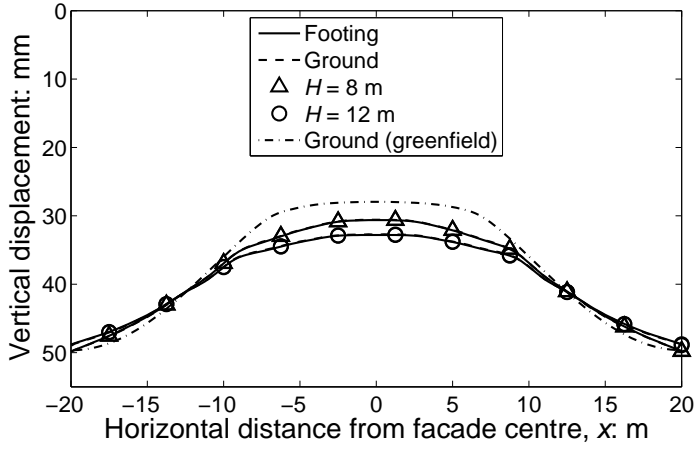

(b)

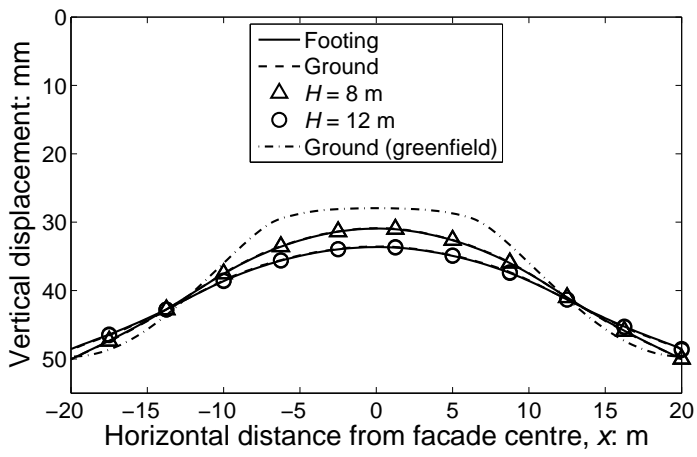

(d)

Figure 7: Vertical displacements at foundation base level induced by tunnelling with $e=0$, compared with greenfield vertical displacements: (a) facade with openings, single tunnel; (b) facade with openings, twin tunnels; (c) plain facade, single tunnel; (d) plain facade, twin tunnels 


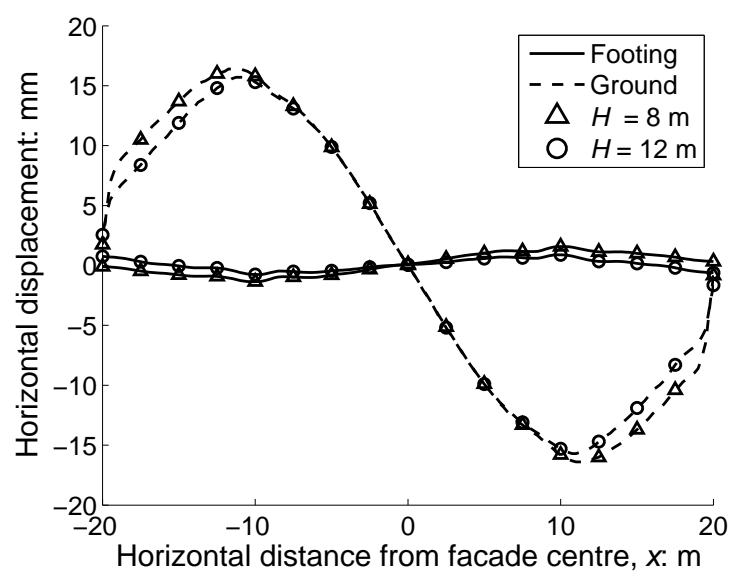

(a)

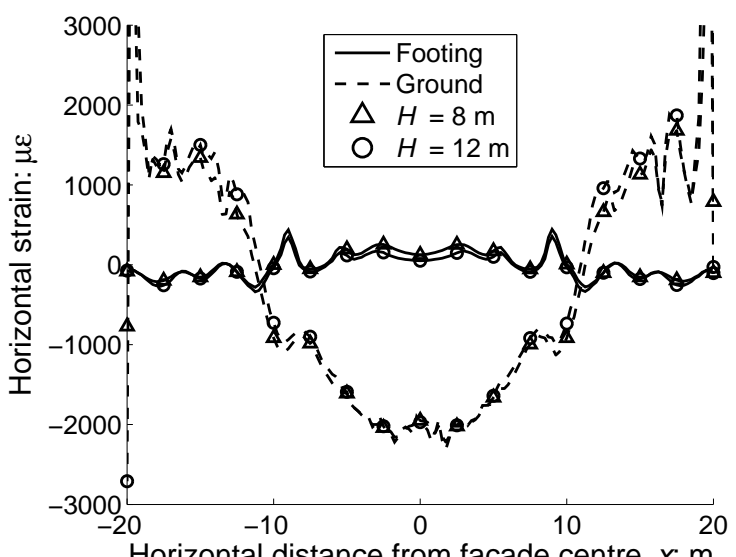

(c)

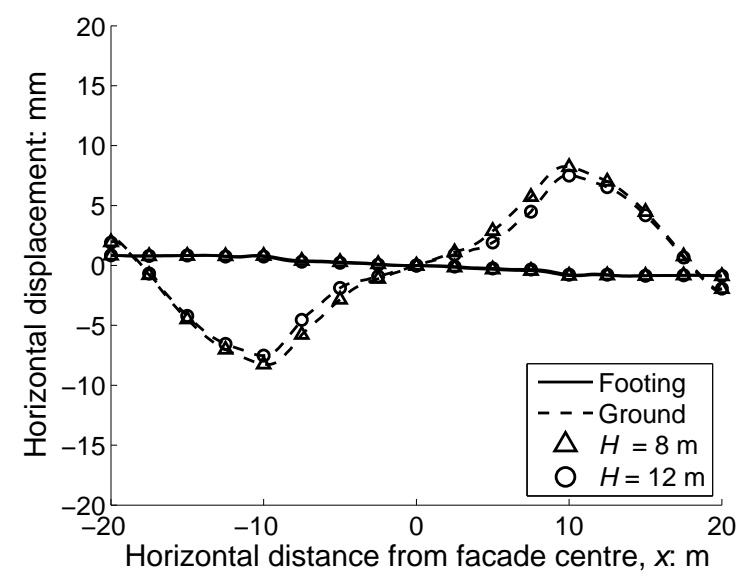

(b)

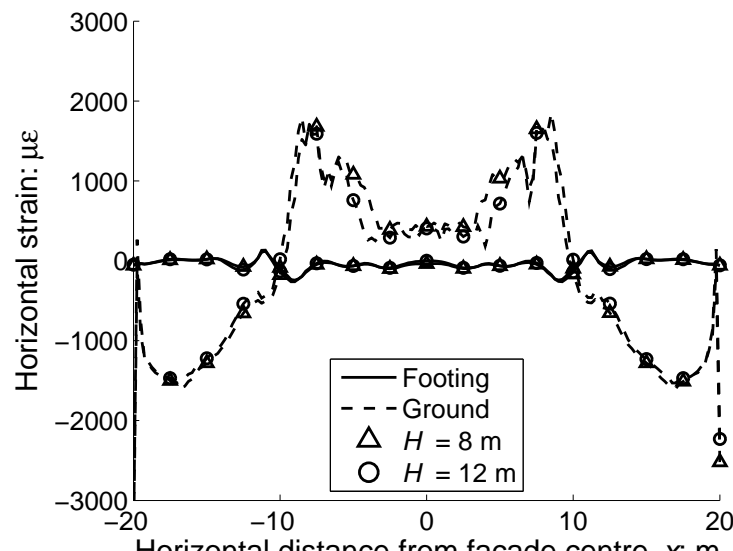

(d)

Figure 8: Horizontal displacements and horizontal strains at foundation base level induced by tunnelling with $e=0$ : (a) horizontal displacement, single tunnel; (b) horizontal displacement, twin tunnels; (c) horizontal strain, single tunnel; (d) horizontal strain, twin tunnels 


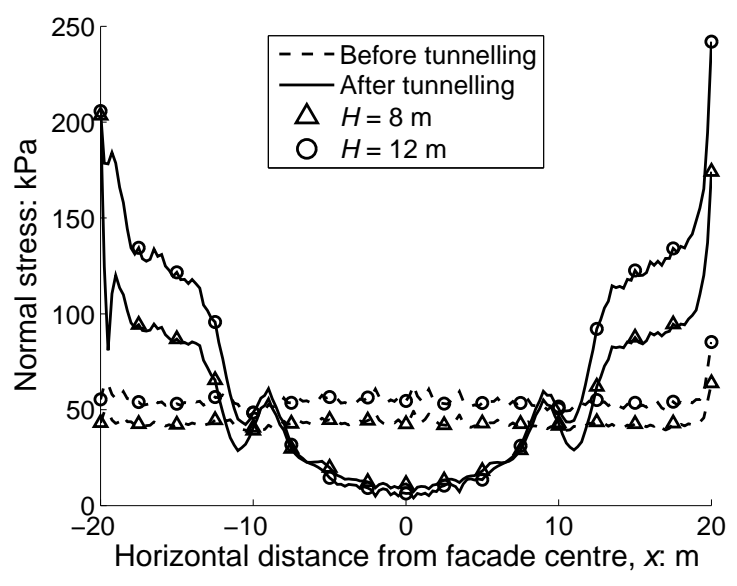

(a)

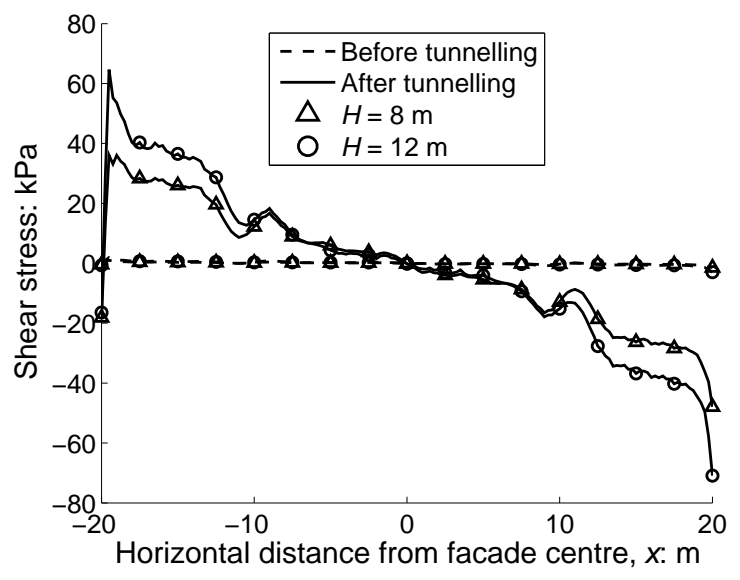

(c)

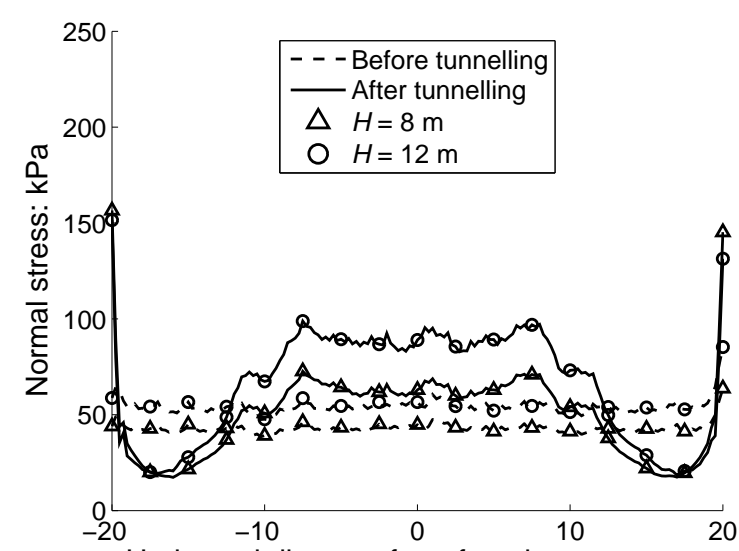

(b)

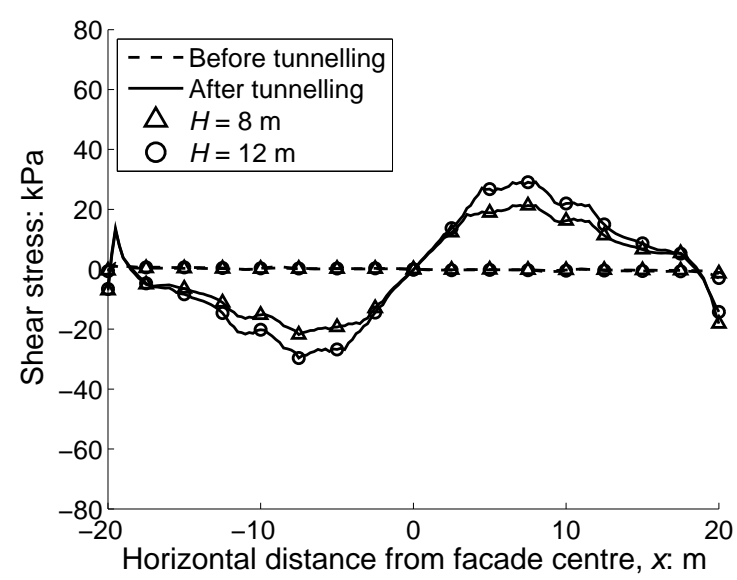

(d)

Figure 9: Contact stresses on foundation base, before and after tunnelling with $e=0$ : (a) normal stress, single tunnel; (b) normal stress, twin tunnels; (c) shear stress, single tunnel; (d) shear stress, twin tunnels. Normal stresses are compression positive; shear stresses are positive when applied to the foundation in the positive $x$-direction 

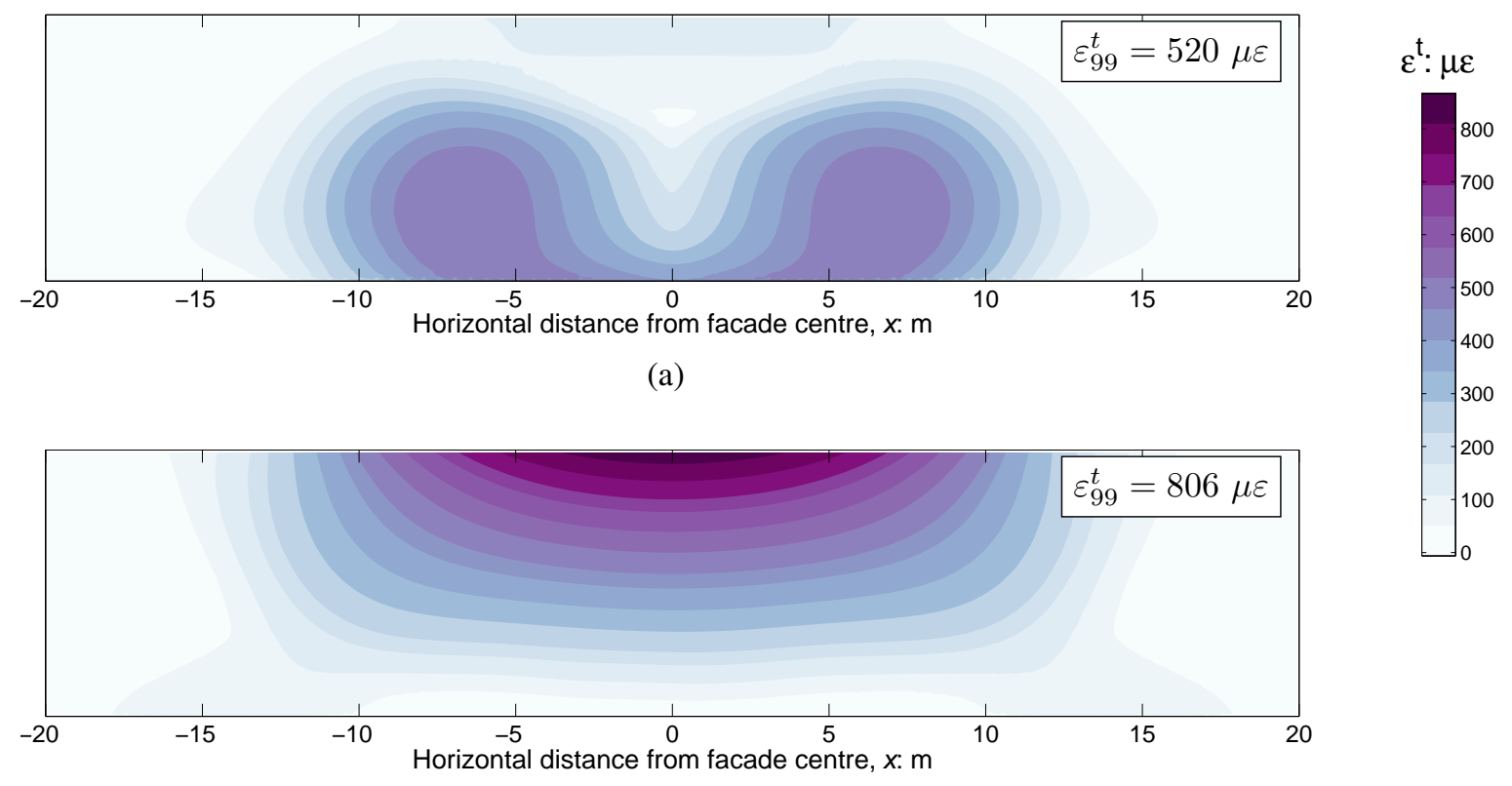

(b)
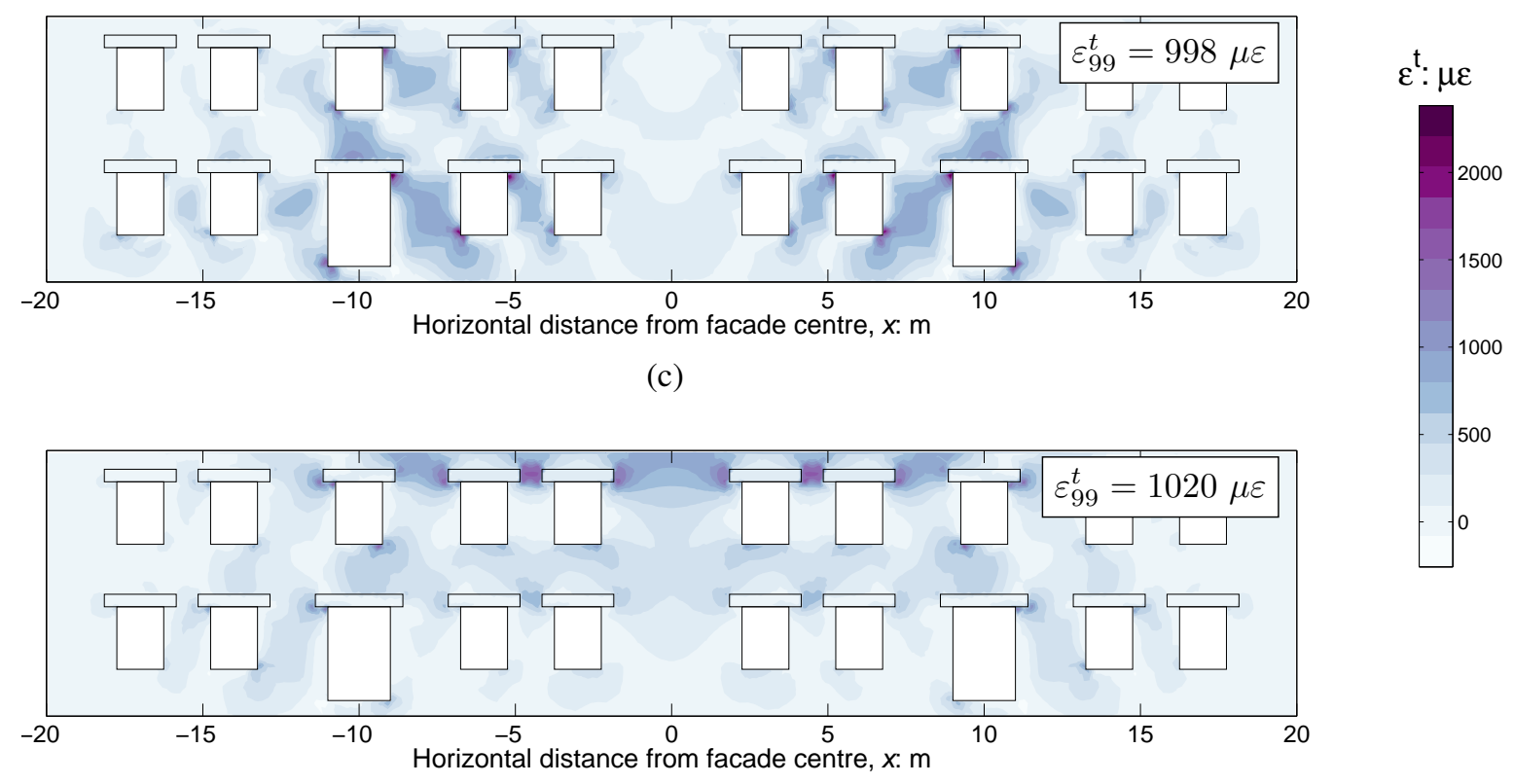

(d)

Figure 10: Major principal strains $\varepsilon^{t}$ and characteristic strain $\varepsilon_{99}^{t}$ in facades of height $H=8 \mathrm{~m}$ induced by tunnelling with $e=0$ : (a) plain facade, single tunnel; (b) plain facade, twin tunnels; (c) facade with openings, single tunnel; (d) facade with openings, twin tunnels 


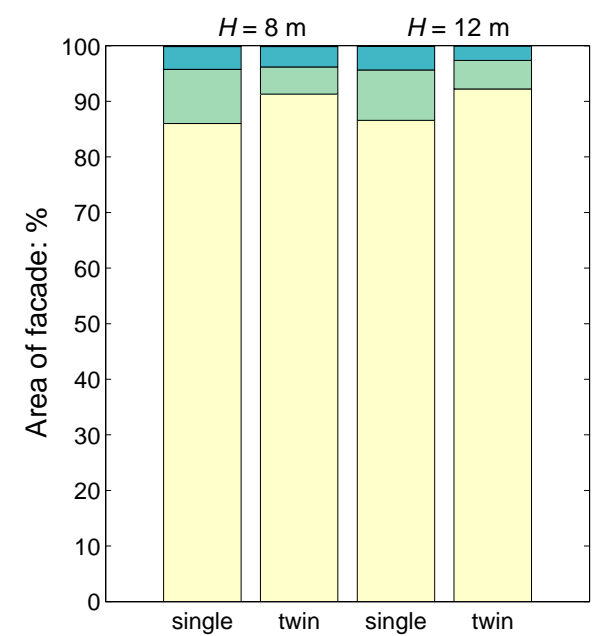

(a)

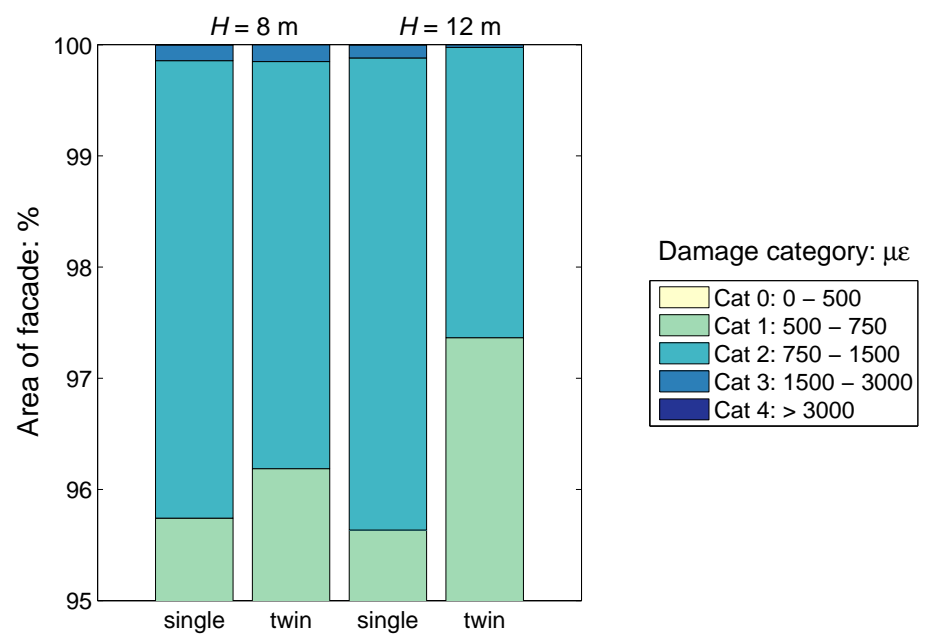

(b)

Figure 11: Building damage bar charts for isolated facades of height $H=8 \mathrm{~m}$ and $12 \mathrm{~m}$ for single and twin tunnels with $e=0$ : (a) complete range of cumulative facade area; (b) detail showing range between $95 \%$ and $100 \%$ 


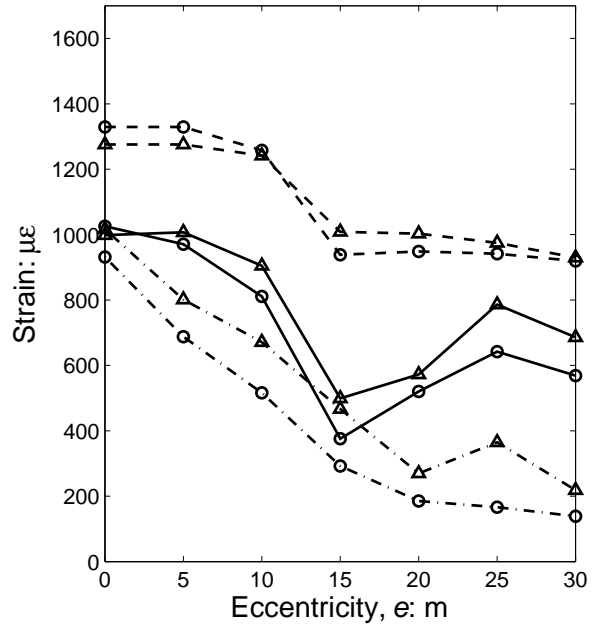

(a)

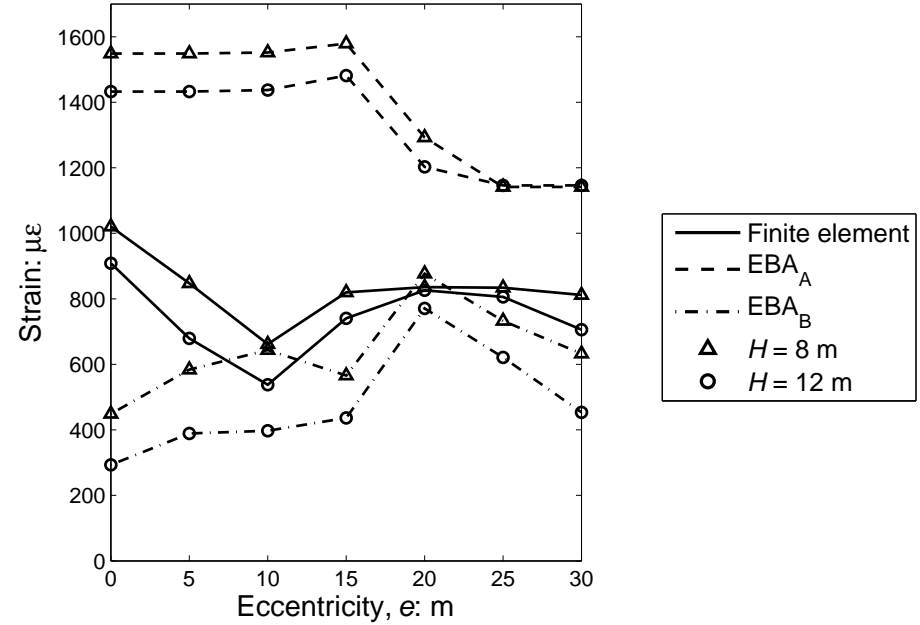

(b)

Figure 12: Variation with eccentricity of characteristic strain $\varepsilon_{99}^{t}$ and the maximum tensile strain determined from the EBA method, for facades of height $H=8 \mathrm{~m}$ and $12 \mathrm{~m}$ : (a) single tunnel; (b) twin tunnels 
building centre line

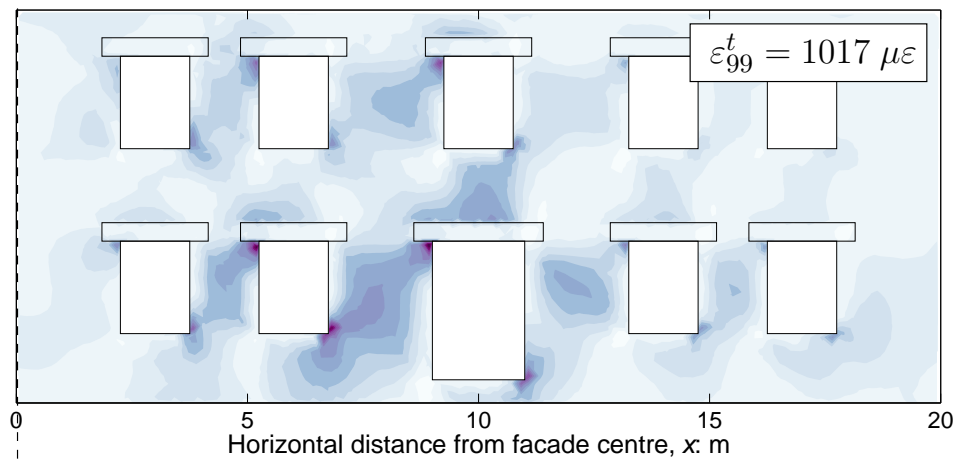

(a)

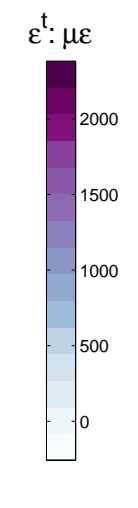

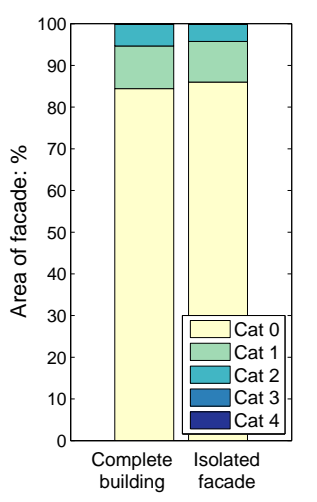

(b)

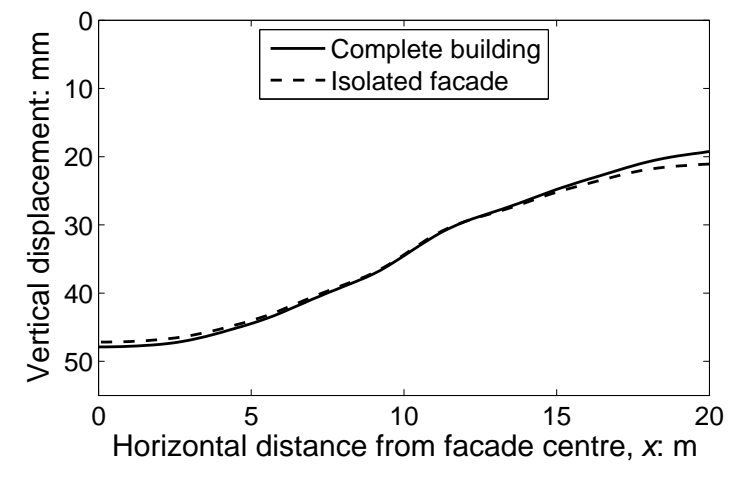

(c)

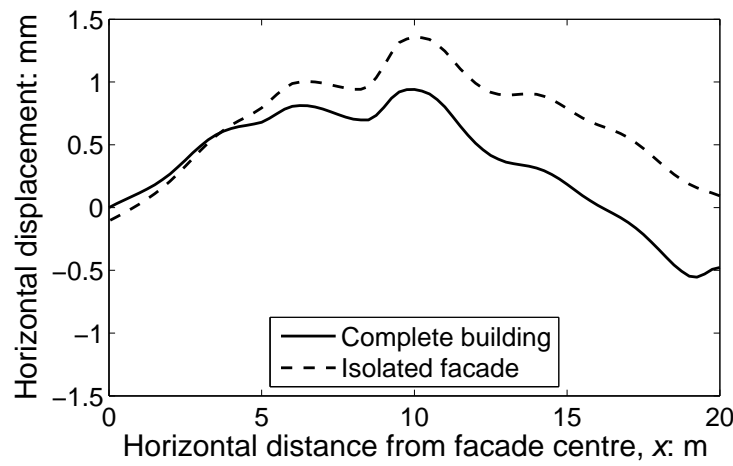

(d)

Figure 13: Front facade data from complete building analysis with $H=8 \mathrm{~m}$ for single tunnel with $e=0$, compared with data from corresponding isolated facade analysis: (a) major principal strains $\varepsilon^{t}$ (same scale as in Fig. 10(c)) and characteristic strain $\varepsilon_{99}^{t}$; (b) building damage bar chart; (c) vertical displacement of base of footing; (d) horizontal displacement of base of footing 


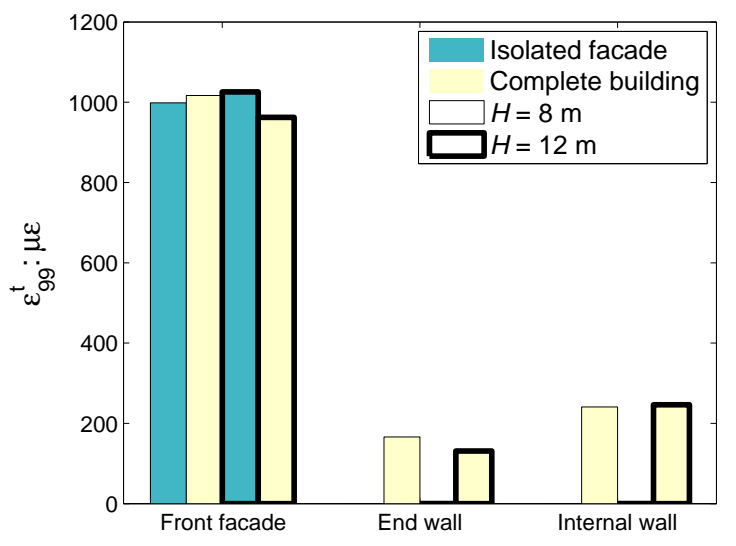

(a)

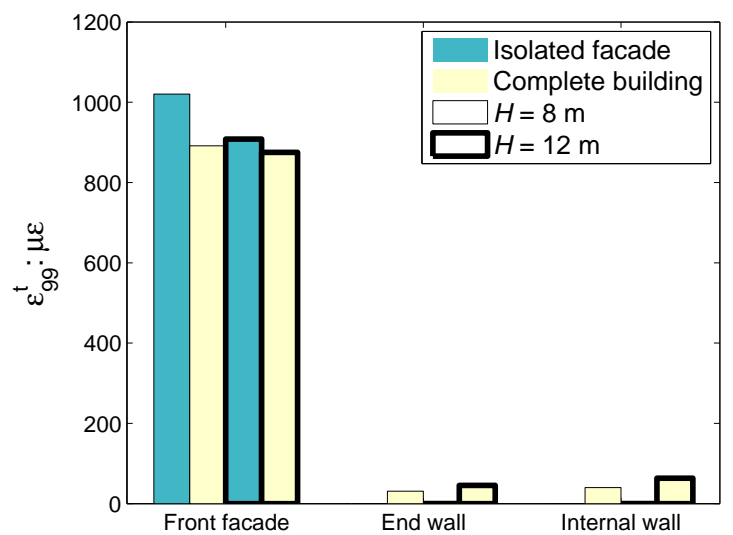

(b)

Figure 14: Comparison of characteristic strains induced in individual facades (and return walls) of height $H=8 \mathrm{~m}$ and $12 \mathrm{~m}$, obtained from isolated facade and complete building analyses for tunnels with $e=0$ : (a) single tunnel; (b) twin tunnels 


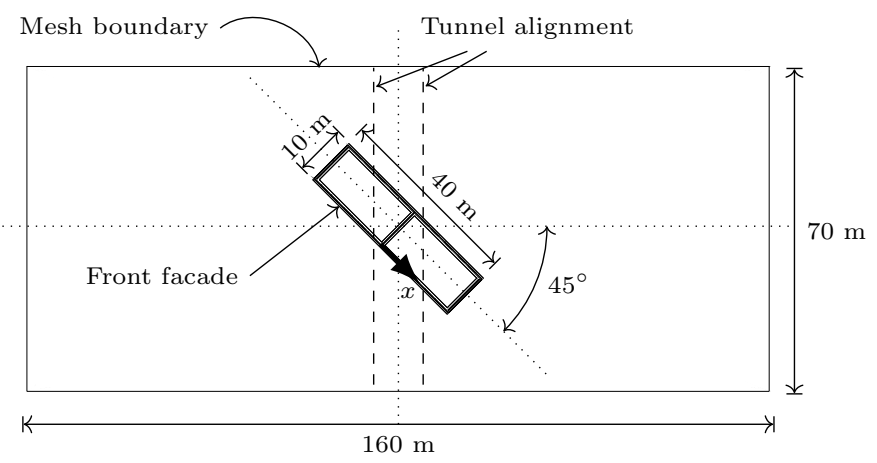

(a)

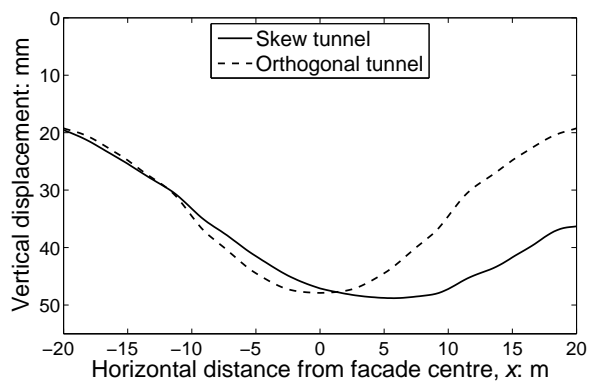

(b)

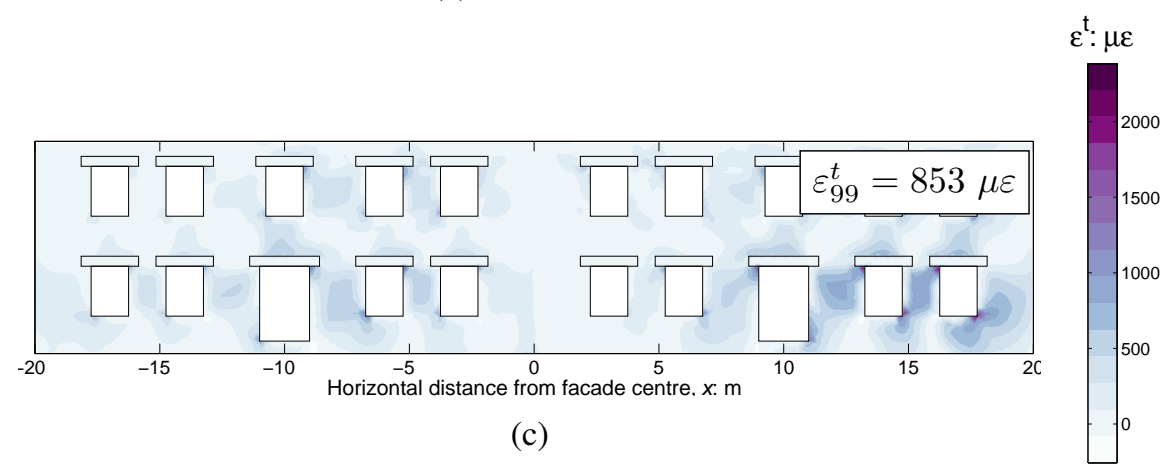

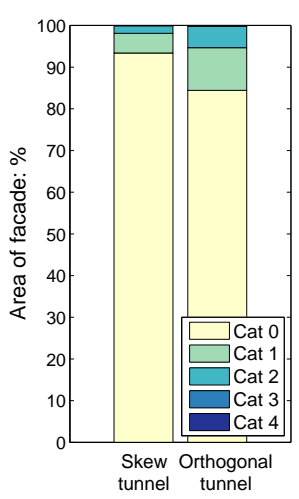

(d)

Figure 15: Front facade data from complete building analysis with $H=8 \mathrm{~m}$ for skew single tunnel at $45^{\circ}$, compared with data from complete building analysis with $H=8 \mathrm{~m}$ and orthogonal single tunnel with $e=0$ : (a) plan view of the mesh showing relative position of complete building and skew tunnel; (b) vertical displacement of base of footing; (c) major principal strains $\varepsilon^{t}$ (same scale as in Figs 10(c) and 13(a)) and characteristic strain $\varepsilon_{99}^{t}$; (d) building damage bar chart 


\section{References}

Addenbrooke, T. I. \& Potts, D. M. (2001). Twin tunnel interaction: surface and subsurface effects. International Journal of Geomechanics 1, No. 2, 249-271.

Addenbrooke, T. I., Potts, D. M. \& Puzrin, A. M. (1997). The influence of pre-failure soil stiffness on the numerical analysis of tunnel construction. Géotechnique 47, No. 3, 693-712.

Amorosi, A., Boldini, D., de Felice, G., Malena, M. \& Sebastianelli, M. (2014). Tunnelling-induced deformation and damage on historical masonry structures. Géotechnique 64, No. 2, 118-130.

Bilotta, E., Paolillo, A., Russo, G. \& Aversa, S. (2017). Displacements induced by tunnelling under a historical building. Tunnelling and Underground Space Technology 61, 221-232.

Boscardin, M. D. \& Cording, E. J. (1989). Building response to excavation-induced settlement. Journal of Geotechnical Engineering 115, No. 1, 1-21.

Burd, H. J., Houlsby, G. T., Augarde, C. E. \& Liu, G. (2000). Modelling tunnelling-induced settlement of masonry buildings. Proc. Instn Civ. Engrs Geotech. Engng 143, No. 1, 17-29.

Burland, J. B. (2001). Assessment methods used in design. Building Response to Tunnelling, London 1, 23-43.

Burland, J. B., Chapman, T., Skinner, H. D. \& Brown, M. (2012). ICE Manual of Geotechnical Engineering.

Burland, J. B., Mair, R. J. \& Standing, J. R. (2004). Ground performance and building response due to tunnelling. Advances in Geotechnical Engineering, Institution of Civil Engineers. Edited by R.J. Jardine, D.M. Potts, and K.G. Higgins 1, 291-342.

Burland, J. B. \& Wroth, C. P. (1974). Settlement of buildings and associated damage. In Conference on Settlement of Structures, Pentech Press, pp. 611-654.

Crossrail (accessed January 31, 2017). A new railway for London and the south east. http://www.crossrail.co.uk/.

Dimmock, P. S. \& Mair, R. J. (2008). Effect of building stiffness on tunnelling-induced ground movement. Tunnelling and Underground Space Technology 23, No. 4, 438-450. 
Doherty, J. P. \& Muir Wood, D. (2013). An extended Mohr-Coulomb (EMC) model for predicting the settlement of shallow foundations on sand. Géotechnique 63, No. 8, 661-673.

Dong, Y. P., Burd, H. J. \& Houlsby, G. T. (2016). Finite-element analysis of a deep excavation case history. Géotechnique 66, No. 1, 1-15.

Dulake, C. (2011). Crossrail design and construction / Crossrail Entwurf, Bemessung und Ausführung. Geomechanics and Tunnelling 4, No. 5, 592-604.

Fargnoli, V., Gragnano, C. G., Boldini, D. \& Amorosi, A. (2015). 3D numerical modelling of soilstructure interaction during EPB tunnelling. Géotechnique 65, No. 1, 23-37.

Farrell, R. P., Mair, R. J., Sciotti, A. \& Pigorini, A. (2014). Building response to tunnelling. Soils and Foundations 54, No. 3, 269-279.

Furtmuller, T. \& Adam, C. (2011). Numerical modeling of the in-plane behaviour of historical brick masonry walls. Acta Mechanica 221, 65-77.

Giardina, G., Hendriks, M. A. N. \& Rots, J. G. (2013). Numerical analysis of a masonry facade subject to tunnelling-induced settlements. Engineering Structures 54, 234-247.

Harris, D. I. (2001). Compensation grouting for the Royal Automobile Club building. Building Response to Tunnelling 2, 367-385.

Harris, D. I. \& Franzius, J. N. (2005). Settlement assessment for running tunnels-a generic approach. In Proc. 5th Int. Symp. Geotechnical Aspects of Underground Construction in Soft Ground, Amsterdam, pp. 225-230.

Hills, D. A. \& Dini, D. (2011). Characteristics of the process zone at sharp notch roots. International Journal of Solids and Structures 48, No. 14, 2177-2183.

Houlsby, G. T. (1999). A model for the variable stiffness of undrained clay. Proc. Int. Symp. on PreFailure Deformation Characteristics of Soils, Turin 1, 443-450.

Jurečič, N., Zdravković, L. \& Jovičić, V. (2013). Predicting ground movements in London Clay. Proc. Instn Civ. Engrs Geotech. Engng 166, No. 5, 466-482.

Lee, J. \& Fenves, G. (1998). Plastic-damage model for cyclic loading of concrete structures. Journal of Engineering Mechanics 124, No. 8, 892-900. 
Losacco, N., Burghignoli, A. \& Callisto, L. (2014). Uncoupled evaluation of the structural damage induced by tunnelling. Géotechnique 64, No. 8, 646-656.

Mair, R. J., Taylor, R. N. \& Burland, J. B. (1996). Prediction of ground movements and assessment of risk of building damage due to bored tunnelling. In Proc. 4th Int. Symp. Geotechnical Aspects of Underground Construction in Soft Ground, AA Balkema, pp. 713-718.

Marshall, A., Farrell, R. P., Klar, A. \& Mair, R. J. (2012). Tunnels in sands: the effect of size, depth and volume loss on greenfield displacements. Géotechnique 62, No. 5, 385.

NCE (2009). Delivering Crossrail: Major project report. New Civil Engineer 09, 1-58.

New, B. M. \& O'Reilly, M. P. (1991). Tunnelling induced ground movements: predicting their magnitude and effects. Proc. of the 4th Int. Conf. on Ground Movements and Structures, Cardiff, Pentech Press, London, 671-697.

O’Reilly, M. P. \& New, B. M. (1982). Settlements above tunnels in the United Kingdom-their magnitude and prediction. Tunnelling ' $82,173-181$.

Pickhaver, J. B., Burd, H. J. \& Houlsby, G. T. (2010). An equivalent beam method to model masonry buildings in 3D finite element analysis. Computers and Structures 88, No. 19/20, 1049-1063.

Potts, D. M. \& Addenbrooke, T. I. (1997). A structure's influence on tunnelling-induced ground movements. Proc. Instn Civ. Engrs Geotech. Engng 125, No. 2, 109-125.

Sloan, S. W., Abbo, A. J. \& Sheng, D. (2001). Refined explicit integration of elastoplastic models with automatic error control. Engineering Computations 18, No. 1/2, 121-194.

Truong-Hong, L. \& Laefer, D. F. (2013). Impact of modeling architectural detailing for predicting unreinforced masonry response to subsidence. Automation in Construction 30, 191-204.

Viggiani, G. \& Standing, J. R. (2001). The Treasury. Building Response to Tunnelling 2, 401-432.

Wisser, C., Augarde, C. E. \& Burd, H. J. (2005). Numerical modelling of compensation grouting above shallow tunnels. Int. J. for Numer. and Anal. Meth. in Geomech. 29, No. 5, 443-471.

Withers, A. D. (2001). Murdoch, Neptune and Clegg Houses in Moodkee Street, Rotherhithe. Building Response to Tunnelling 2, 811-828. 
Withers, A. D., Page, D. P. \& Linney, L. F. (2001). Geology and geotechnical properties. Building Response to Tunnelling 1, 57-81.

Wongsaroj, J., Soga, K. \& Mair, R. J. (2007). Modelling of long-term ground response to tunnelling under St James's Park, London. Géotechnique 57, No. 1, 75-90.

Yiu, W. N., Burd, H. J. \& Martin, C. M. (2017). Soil-building interaction in finite element analysis of tunnelling-induced building damage. In Proc. IV International Conference on Computational Methods in Tunneling and Subsurface Engineering, pp. 381-388. 